\title{
Harnessing Alternative Narratives of the City: Exploring the Generative Capacity of Skateboarding.
}

\author{
Christopher Cormier B. Env. Des.
}

\author{
A thesis submitted to the Faculty of Graduate and Postdoctoral Affairs \\ in partial fulfillment of the requirements for the degree of \\ Master of Architecture \\ in \\ Architecture \\ Carleton University \\ Ottawa, Ontario \\ (c) 2014 \\ Christopher Cormier
}




\section{[Abstract]}

I have a keen interest in the generative capacity of cities. As city-dwelling populations continue to increase, it is vitally important for architects to look beyond the traditional boundaries of the profession and view their work within the larger context of the urban fabric. By doing so, architects open up possibilities by which the generative capacity of the city can emerge within the architecture.

One such example is found through the uniquely urban practice of skateboarding; skateboarding acts as a criticism of contemporary architecture, placing engagement and use above economics and the traditional imperatives of architecture. As demonstrated in a case study and design proposal for the Booth Board Mill on Chaudière Island, the skateboarding ethos can provide valuable alternatives to more traditional architectural paradigms. 


\section{[Acknowledgments]}

I would like to thank my advisor, Kelly Crossman, for his support and guidance throughout this process.

I would like to thank Courtney Symons, Joel Sprinkle, Brogan Van, and all my friends and family who helped give shape to this project in ways they may never fully understand.

Most importantly I would like to thank my fiancée, Randi Haberman. Your understanding and support over the past 8 years has been instrumental, in both completing this degree, and in making me the person I am today. 


\section{[Table of Contents]}

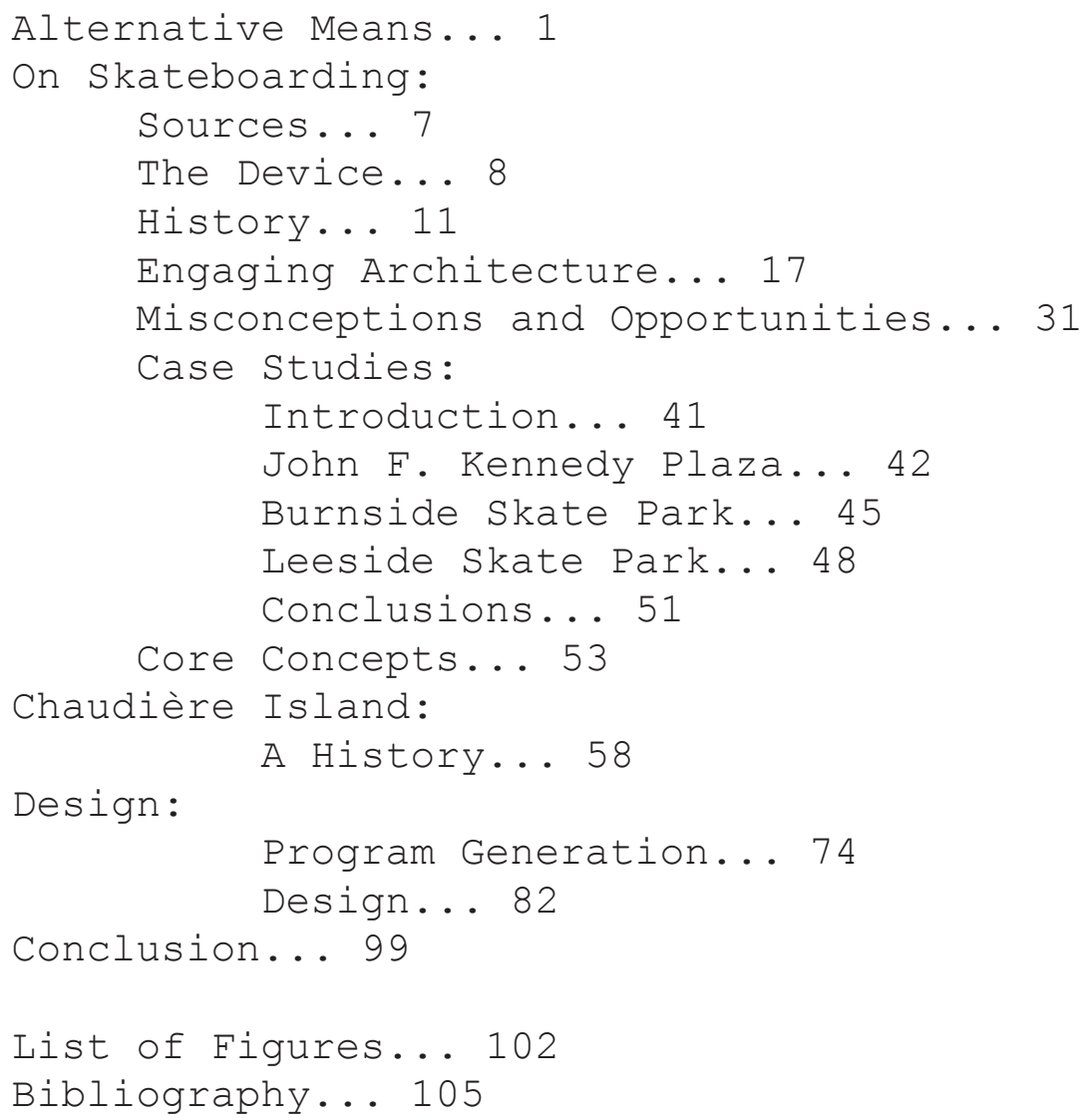




\section{[Alternative Means]}

At the current point in human history, the migration of people from rural populations into the city is both unquestionable and unprecedented. In his work Narrative Architecture, Nigel Coates posits that the city's "risk of uncertainty and danger is easily outweighed by the promise of opportunity," moreover; "the open-ended world of the city is, relatively speaking, without limits. It satisfies the need for repetition, but also the urge to encounter the unknown, to combine the well rehearsed with the unpredictable." ${ }^{1}$ The idealized city and the lived reality of the city are, however, two very different things.

Indeed, "although conceived as an efficient rationally functioning organism, the city combines a myriad of experiences that were never intended by any of its makers." ${ }^{2}$ Out of this rationally functioning organism has emerged a wide variety of different user groups and experiences, but for the 1 Coates, Nigel. Narrative architecture. Chichester, West Sussex: Wiley, 2012. 33.

2 Coates, Narrative architecture. 34. 
purpose of this examination it is the actions of one particular group that is of interest: skateboarders. Despite facing prejudice, being legislated against, and being largely written-off as a juvenile hobby, skateboarding and skateboarders in particular provide a important critique of architecture and the urban fabric.

Dr. Iain Borden, former Director and Head of the Bartlett School of Architecture, remarked that "decades of urban technology have unwittingly created a concrete playground of immense potential, and that it sometimes takes the mind of a 12-year-old to realize this potential."3 ${ }^{\text {Speaking, of }}$ course, about skateboarding, Dr. Borden undertakes a rigorous assessment of the relation between skateboarding and architecture in his seminal work Skateboarding, Space, and the City. According to Dr. Borden, the city for a skateboarder is a kind of

3 Borden, lain. Strangely familiar: narratives of architecture in the city. London: Routledge, 1996. 85. 
"capriccio" stemming from the "discontinuous edit of architecture and urban space," wherein they recompose the city "from different places, locations, urban elements, routes and times, involving the twin processes of asyndeton (omitting certain elements) and synecdoche (substituting one part for another, or the whole)." 4 As Dr. Borden points out, there are grounds here

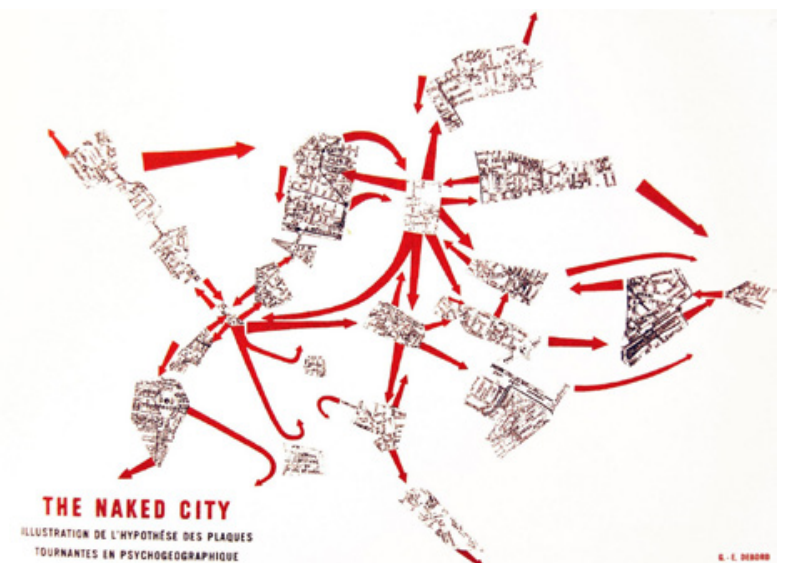

Figure 1: The Naked City (1957), Guy Debord for a comparison between skateboarding and

the Situationist International movement of

the mid-20th century Paris.

Guy Debord's The Naked City (Figure 1)

serves as the archetypal Situationist

International work, which is an image

of Paris that is "part factual and part

experiential." ${ }^{5}$ Showing the city of Paris

$4 \quad$ Borden, lain. Skateboarding, space and the city: architecture and the body. Oxford:Berg, 2001. 219.

5 Coates, Narrative architecture. 36. 
as a collection of map fragments and arrows illustrating flow, Nigel Coates continues: "The message is that citizens should not take the city at face value, but deconstruct it, making space for their own existence as well as those hostile forces within it." 6

Dr. Borden illustrates a remarkable connection to Debord via Coates in that skateboarders are "both framed by, and exploitative of, the physical space-time of modernist urban space."7 When navigating the city, skateboarders analyze the built environment as it exists as a skateable surface; they disregard any

$6 \quad$ Coates, Narrative architecture. 36.

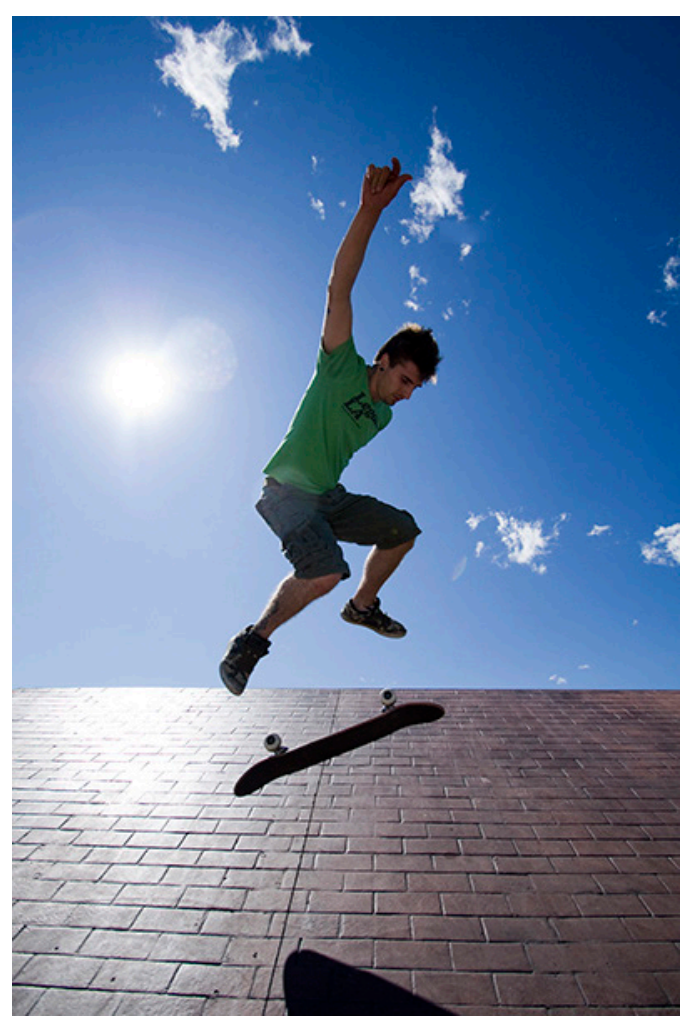

Figure 2: Skateboarder preforming a kickflip. 
and all "historical, symbolic or authorial content." ${ }^{8}$ Skateboarders seem to respond directly to the Situationist's call and take the city for themselves in both literal (through appropriation) and metaphoric terms as a result of a phenomenon know as "skater's eye."9

Indeed, the Situationist "'maps' composed from the opportunities offered by the physical and emotional contours of the city... enacted through a run across different spaces and moments" shares a considerable similarity to skateboarders" "mental knowledge of highly detailed local knowledge about dispersed places, micro-architecture and accessible times."10 Thus, with skateboarding grounded in popular architectural discourse, a thorough examination of its practice is necessary to reveal the skateboarding ethos, as well as how and why it should be incorporated into architectural design.

\begin{tabular}{ll}
\hline 8 & Borden, Skateboarding... 218. \\
9 & Borden, Skateboarding...2 218. \\
& See Also: "Skater's Eye." Thrasher, March 1, 1997.71. \\
10 & Borden, Skateboarding... 223.
\end{tabular}




\section{[On Skateboarding: Sources]}

As mentioned previously, Skateboarding, Space, and the City by Dr. Iain Borden is a hugely important book for skateboarding; it provided the first complete and thorough examination of skateboarding, the intent of which was to move the sport away from its marginal position in society and into serious academic discussions. Dr. Borden himself mentions a handful of publications regarding skateboards and skateboarding in his introduction but notes that "none of these [other publications], however, is explicitly concerned with the kinds of cultural, spatial, architectural, and urban issues which [are] address[ed] here."11 As such, Dr. Borden's book serves as a primary source for a significant portion of this work, and indeed, the vast majority of all scholarly discourses on skateboarding.

11 Borden, Skateboarding... 5. 


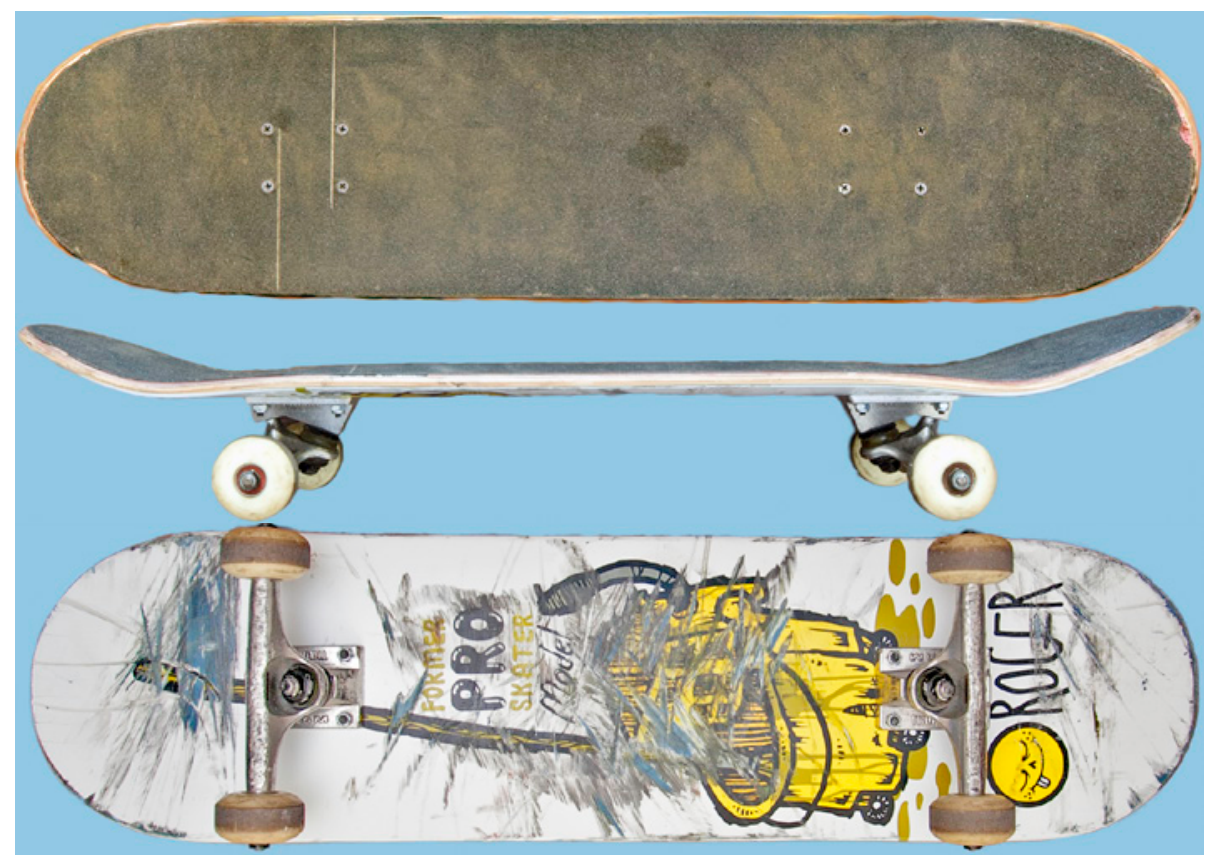

[On Skateboarding: The Device]

Over the course of its history, skateboarding has enjoyed several waves of popularity: from the production of the first commercial skateboard in 1959 to the mid-1960s; in the mid-1970s the invention Figure 3: A skateboard viewed from the top, side and bottom of the polyurethane wheel made skateboards more maneuverable; in the late-1980s new skateboard designs and techniques were invented and the modern "street-style" was developed. ${ }^{12}$

12 Encyclopædia Britannica Online, s. v. "skateboarding", accessed November 24, 2013, http://www.britannica.com/EBchecked/topic/547332/skateboarding. 
Skateboards today have a relatively simple construction consisting of:

1. A platform surface, generally made of hardwood veneers glued and molded together known as the "deck." The top of the deck is covered with an abrasive material which is little more than heavy-duty sandpaper, known as "grip tape," which provides grip for the skateboarder's feet. Many maneuvers performed on a skateboard consist of balancing with the skateboard as it slides along an obstacle on one section of the deck or another.

2. Two metal hangars known as "trucks" which pivot independently, allowing the skateboard to turn as well as providing another point of contact between the skateboarder and obstacle by which maneuvers are performed.

3. Four polyurethane wheels ranging, in diameter from 49-58mm, with two inset ball bearings per wheel. 


\section{[On Skateboarding: History]}

Originating in southern California, skateboarding began as an activity for when the surf was flat, allowing surfers to roll along the "undulating residential sectors as if they were an ocean wave."13 Suburban living provided a number of opportunities for skateboarders to find, adapt and re-conceive these "modernist spaces" as something else - as concrete waves. ${ }^{14}$

In the late $1960 \mathrm{~s}$ and throughout the 1970s, skateboarders began to engage with empty swimming pools in and around suburban Los Angeles. ${ }^{15}$ While this practice began as yet another way to emulate surfing, the unique qualities of skating pools actually began to differentiate skateboarding from surfing in a number of ways which will be discussed in detail 1 ater. ${ }^{16}$ The found spaces of backyard pools were quickly surpassed by built constructions specifically for skateboarding through the $1970 \mathrm{~s}$ but all too

13 Borden, Skateboarding... 29.

14 Ibid, 33.

15 Ibid, 33.

16 Ibid, 33 . 
soon skateboarders, feeling restricted by monetary requirements as well as "certain safety and behavioral standards,"17 began looking for terrain where they could be "more creative and relaxed."18 The development of street skateboarding in the early 1980s provided not just new terrains, but a new mode of engagement with the city; everything from a highway barricade to a park bench became skateable. ${ }^{19}$ Since its development, street style skateboarding has become the most widely practiced form of skateboarding, even today.

17 Borden, Skateboarding... 133.

18 Ibid, 133

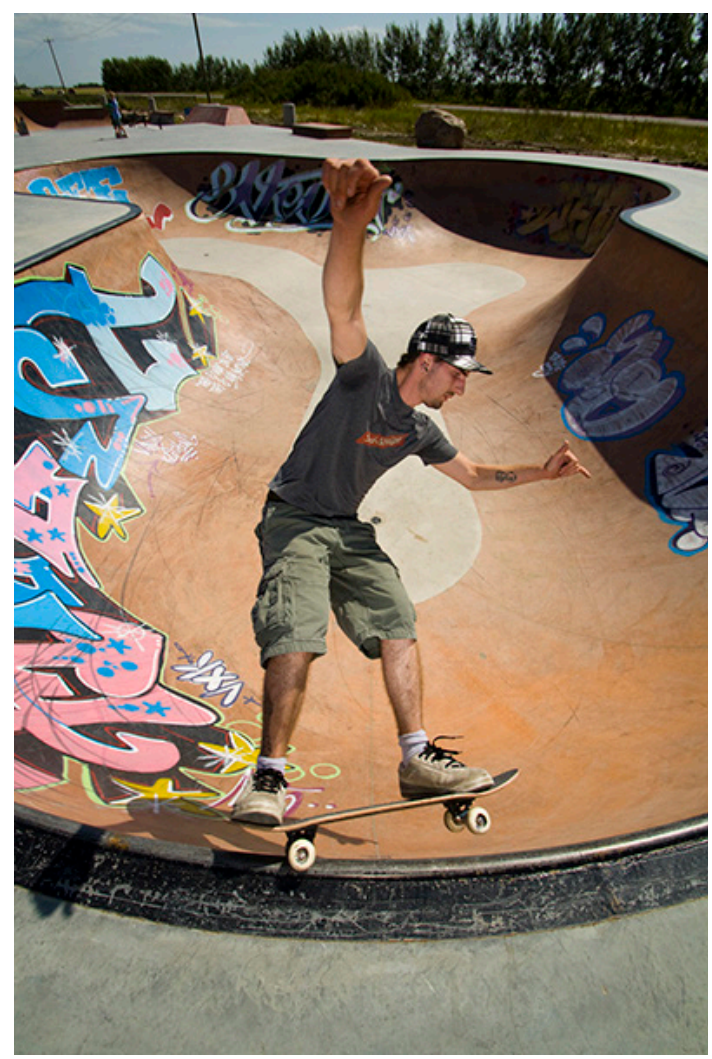

Figure 4: A Skateboarder riding in a purpose-built pool 
Part of the draw to skateboarding and street skateboarding in particular is that it is "immediately accessible to anyone with a skateboard, just step outside."20 The downside of this is that tracking actual participation rates is quite difficult. In 2006, the New York Times wrote that the skateboard industry did approximately \$5.5 billion dollars (USD) worth of sales per year. ${ }^{21}$ American participation rates vary but according to Dr. Ocean Howell, market research indicated that the number of skateboarders was over the 12 million mark in 2005 while participation rates for more traditional sports were 9.9 million and 14.6 million for football and baseball respectively. ${ }^{22}$ While these type of figures are not available for Canada, our close economic and social ties with the United States allow for some extrapolation of this

20 Borden, Skateboarding... 182.

$21 \quad$ Higgins, Matt. "In Board Sports, Insider Status Makes Gear Sell." New York Times, November 24, 2006.

22 Howell, Ocean. "Skatepark As Neoliberal Playground: Urban Governance, Recreation Space, And The Cultivation Of Personal Responsibility." Space and Culture 11, no. 4 (2008): 476. 
data. More so than the rest of the country, Western Canada does provide some insight into the popularity of the sport in Canada; the skateboard park directory Skateparktour.ca lists 195 skateboard parks across British Columbia, Alberta, and Saskatchewan. ${ }^{23}$ The city of Vancouver lists eight permanent, public skateboard parks in the city proper, with significantly more located in the greater Vancouver area. ${ }^{24}$ As early as 2005, Vancouver Parks and Recreation had set forth a "Skateboard Strategy" with the intent of "guiding capital investments so that skateparks are successful in the short and long term for all involved."25 Ottawa's under-representation of skateboarders is quite well-known ${ }^{26}$; in the city there are only two permanent

23 "Home - Skateparktour.ca." Skateparktour.ca. http://skateparktour.ca/index.php (accessed November 28, 2013)

24 "Skateboard parks." City Of Vancouver Website. http://vancouver.ca/parks-recreationculture/skateboard-parks.aspx (accessed November 28, 2013).

25 Vancouver Parks and Recreation, Skateboard Strategy for Vancouver, (Vancouver: Unknown, 2005), http://vancouver.ca/files/cov/2005-Skateboard-Strategy.pdf

26 Smith, Teresa. "No shelter for skateboarders." Ottawa Citizen, January 1, 2013. http://www.ottawacitizen.com/sports/shelter+skateboarders/7762534/story.html (accessed November 26, 2013). 
skateboard parks ${ }^{27}$ while Edmonton, a city of comparable population has five permanent parks. ${ }^{28}$

Now, having laid out skateboarding's distinct and unique history, as well as its current reach or participation rates, we can begin to examine the relationship between skateboarding and architecture.

27 "Skateboarding parks." City of Ottawa. http://ottawa.ca/en/residents/parks-andrecreation/parks-and-sports-fields/skateboarding-parks (accessed November 28, 2013).

28 "Attractions \& Recreation - Skateparks." City of Edmonton. http://www.edmonton.ca/ attractions_recreation/sport_recreation/skateparks.aspx (accessed November 28, 2013). 


\section{[On Skateboarding: Engaging Architecture]}

As architects and designers, we are trained to view our surroundings in a way that is distinctly different than the average citizen: solid/void, mass, color, shape, parti. Skateboarders, too, see the world in a way that is distinctly different than the average citizen but it is through activity and engagement, as well as a "social space-time" and not through formalized education that this process takes place. As mentioned previously, in the $1960 \mathrm{~s}$ and $70 \mathrm{~s}$ skateboarders began riding in empty swimming pools and it is in this setting where their empathy and engagement with architecture can be most easily understood through their relationship with the pool wall. ${ }^{29}$ Indeed, Dr. Borden goes into great detail describing the relation between the body, architecture, surface and materiality which I will recount and elaborate on here (figure 5).

29 Borden, Skateboarding... 34-5. 
As a skateboarder travels along the bottom of the pool on their skateboard they have both momentum ${ }^{30}$ and inertia ${ }^{31}$. As the skateboarder begins to move through the transition from the flat-bottom up the pool wall, they begin to feel compressive force and must resist with their legs to prevent them from collapsing. As the skateboarder feels the effects of inertia, they actually perceive a physical resistance by the architecture on their body as they are redirected up the wall. The second stage is then the release of the compressive force, where after having their inertia re-directed by the architecture, the skateboarder now perceives the verticality of the pool

30 noun (plural momenta /-t /)[mass noun]

1 Physics the quantity of motion of a moving body, measured as a product of its mass and velocity.

From: Oxford English Dictionary. 2nd ed. 20 vols. Oxford: Oxford University Press, 1989.

$31 \quad$ noun [mass noun]

2 Physics a property of matter by which it continues in its existing state of rest or uniform motion in a straight line, unless that state is changed by an external force.

From: Oxford English Dictionary. 2nd ed. 20 vols. Oxford: Oxford University Press, 1989 


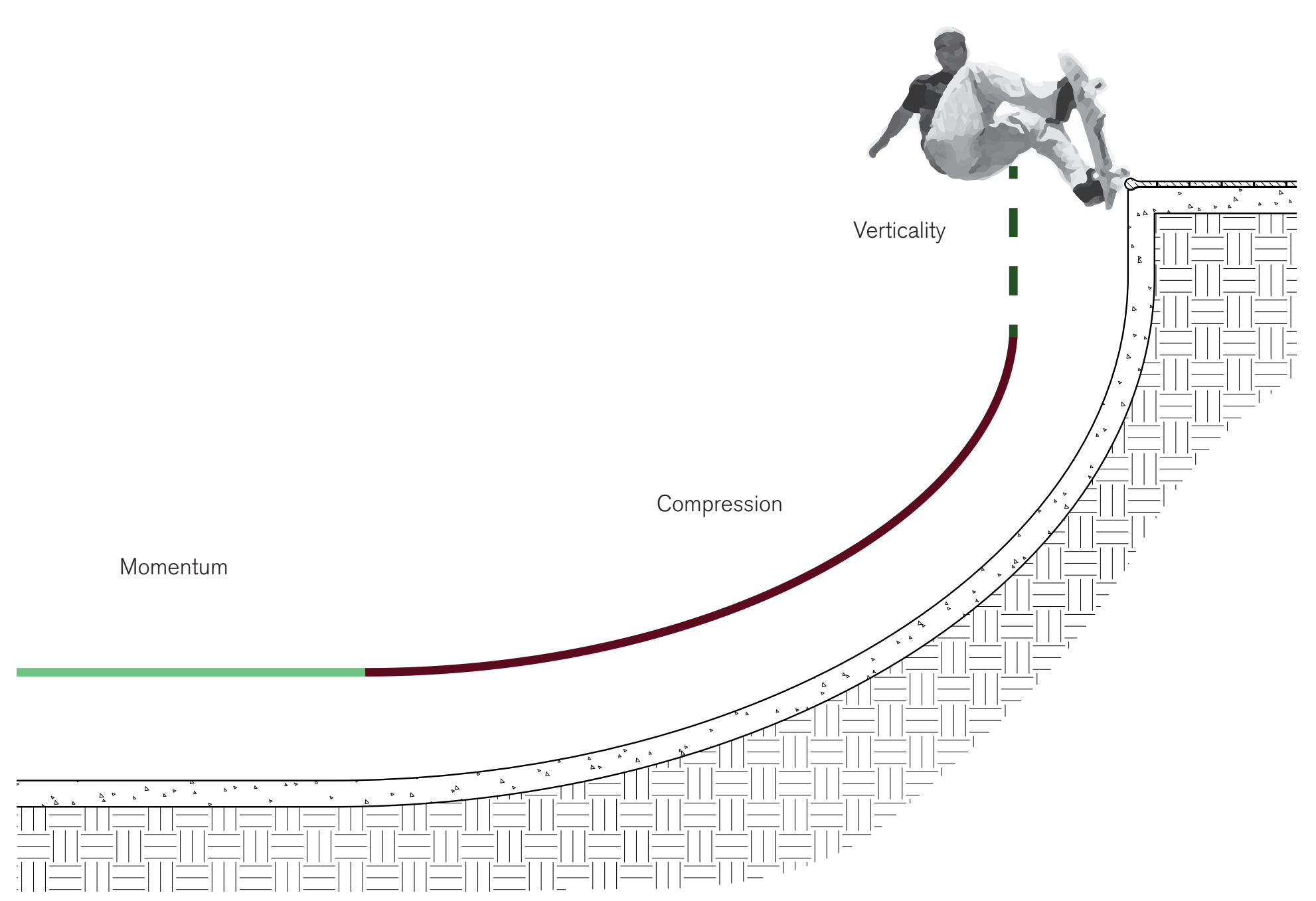

Figure 5 : The physical relation of skateboarder to the pool wall. 
wall as they progress further and further away from the flat-bottom. The third stage is the moment when the skateboarder stalls or hangs momentarily at the peak of their trajectory. While this period of time is quantifiably measured as only fractions of a second, in most cases, the qualitative time-space for the skateboarder is much greater than that. As the skateboarder approaches the lip of the pool, the macro-space that is the pool wall falls away and the skateboarder becomes keenly aware of the micro-space between the skateboard's wheels and the pool tiles. Finally, in the fourth stage the skateboarder begins his descent down the pool wall, through the compression and transition in reverse order that is both similar and different to the ascent. When, as was common in pool sessions, multiple trajectories are performed in sequence as a run or "line," the pattern of ascent-pause-descent is multiplied and begins to form a rhythm or flow that is applied to the space. 
The auditory as well as physical aspects of a skateboarder's experience is of great significance as it is another method by which skateboarders engage with the built environment. Returning to the lip of the pool and an examination of the edge condition, we see the foundations of this auditory engagement. To reach the lip of the pool on a skateboard was - at least during the $60 \mathrm{~s}$ and $70 \mathrm{~s}$ - to reach the edge or the physical limit of a skateboard's capabilities. 32 In order to do this, the grip or materiality of the pool wall needs to be understood. Aside from tactile feedback in the form of vibrations and judder (from surface to wheel, through the trucks and deck and into the skateboarder's feet), skateboarders use sound as a gauge, not just of grip but also of their ascent towards the limit. ${ }^{33}$ Dr. Borden claims there are three distinct sounds as skateboarders work their way closer and closer to the lip of the pool; first comes the fairly uniform white-noise of wheel across concrete that is ubiquitous along the lower regions of the

32 Borden, Skateboarding... 38.

33 Ibid, 35


pool; then comes a clicking noise as wheels pass over the mortar joints in the pool tile immediately below the lip; thirdly is the dull scraping sound as the skateboard slides along the coping tile (figure 6).34 It is at this point where I add two more sounds to Dr. Borden's; fourth is the seemingly shocking sound of silence as the over-zealous skateboarder misjudges their trajectory and launches their board out of

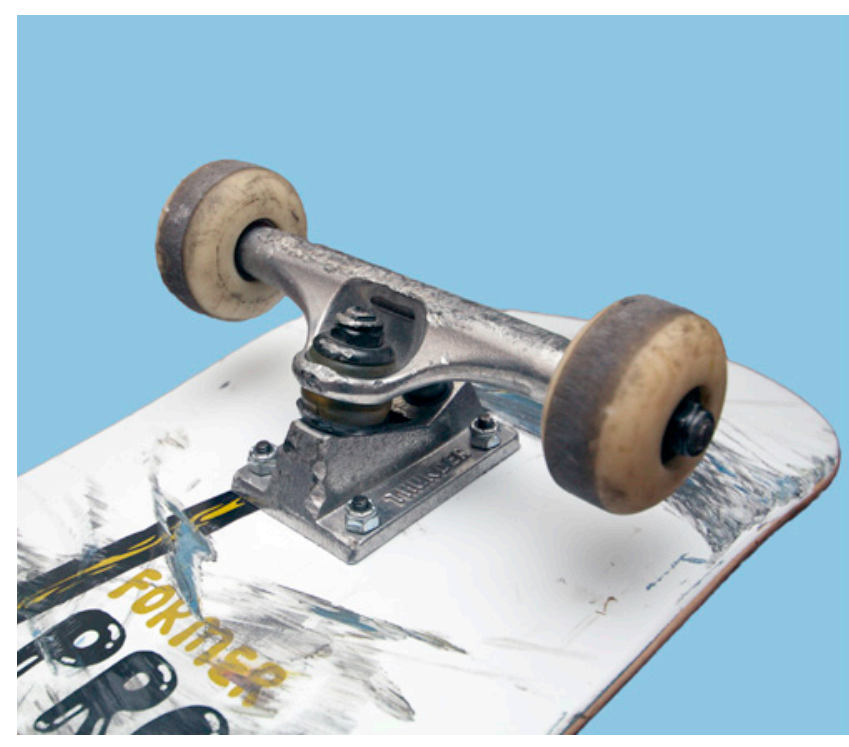

Figure 6: The deck and trucks show visible wear from repeatedly scraping the coping.

the pool which is followed in quick succession by a fifth sound; namely cries of pain as the skateboarder, now sans skateboard, falls from the lip of the pool back to the flat-bottom. Dr. Borden, citing Henri Lefebvre's Production

$34 \quad$ Borden, Skateboarding... 35. 
of Space, reminds us that space is often heard before it is fully seen and "that hearing mediates between the spatial body and the world outside it."35 It is by learning to process auditory as well as visual and tactile stimuli that the skateboarder is able to better gauge trajectory and balance at the absolute limit.

When a skateboarder accidentally overshoots the pool lip and falls to the ground, it is indicative of several different characteristics of skateboarding, namely that as an activity, skateboarding involves a negotiation more so than merely balancing atop a piece of wood. As Dr. Borden points out, "the more proficient skateboarder quickly re-conceived of the skateboard as at once separate to, and part of her or his body, and so integral to their relation to the external world."36 Unlike other games - tennis for example - where the instruments (i.e. the racket) used during

$35 \quad$ Borden, Skateboarding... 35.

36 Ibid, 97 
the game can be said to have unique attitudes and characteristics, once recognized they take on predictable characteristics. This is not the case in skateboarding; skateboards are "less a piece of equipment" and are sometimes noted to "[take] on their own personality... conceiving of the skateboard as having both an autonomous, organic life and a requirement to be brought within the body. ${ }^{37}$ As a result, when attempting to learn or perfect a new maneuver, it is standard practice for skateboarders to do so in familiar or controlled environments. This is an effort by the skateboarder to eliminate extraneous factors that may distract their focus from the board-body relation and the successful completion of the maneuver.

After establishing an understanding of the body-board relation, skateboarders will attempt their newly learned maneuver across different terrain. This is because the terrain through which the skateboarder navigates

37 Borden, Skateboarding... 100. 
also has a role to play in the equation, helping to partially determine the nature of the skateboarder's moves but also by providing a "process of resistance and re-creation."38

In a TEDxUSC talk titled "How context shapes content," professional skateboarder Rodney Mullen - largely considered the most influential street skateboarder of all time - describes, in detail, how skateboarders are constantly working with their personal tool-kit of maneuvers to determine how to best negotiate between their bodies, the board and the terrain. ${ }^{39} \mathrm{Mr}$. Mullen vocalizes what is an intrinsic quality of skateboarding: skateboarding maintains its hold on and engagement with people because of this "board-bodyterrain relation." 40

38 Borden, Skateboarding... 104.

39 Rodney Mullen. "How context shapes content," TEDxUSC video, 17:46, filmed May 2012, posted June 2012, http://youtu.be/gwj|DBjNzXk

40 Borden, Skateboarding... 43. 
Finally, as the skateboarder plummets from the lip of the pool to the flat bottom we are also reminded that negotiations do not always end in favor of the protagonist: attempting again and again is a key element in skateboarding. As Dr. Borden illustrates in regards to the skateboard maneuverer: "skateboarders spend perhaps more time than any other sports practitioners actually failing to do what they attempt."41 This is even more prevalent in street skateboarding where even one successfully completed maneuver, recorded on film or video, is sufficient to move onto increasingly difficult maneuvers (figure 7 ). ${ }^{42}$ With this also comes an almost constant threat of injury and as a result, skateboarders necessarily approach skateboarding with a certain seriousness, both for the activity and the subculture tied to it. ${ }^{43}$ Skateboarding is seen by skateboarders as a lived experience, a

$41 \quad$ Borden, Skateboarding... 121.

$42 \quad$ Ibid, 121.

$43 \quad$ Ibid, 202. 


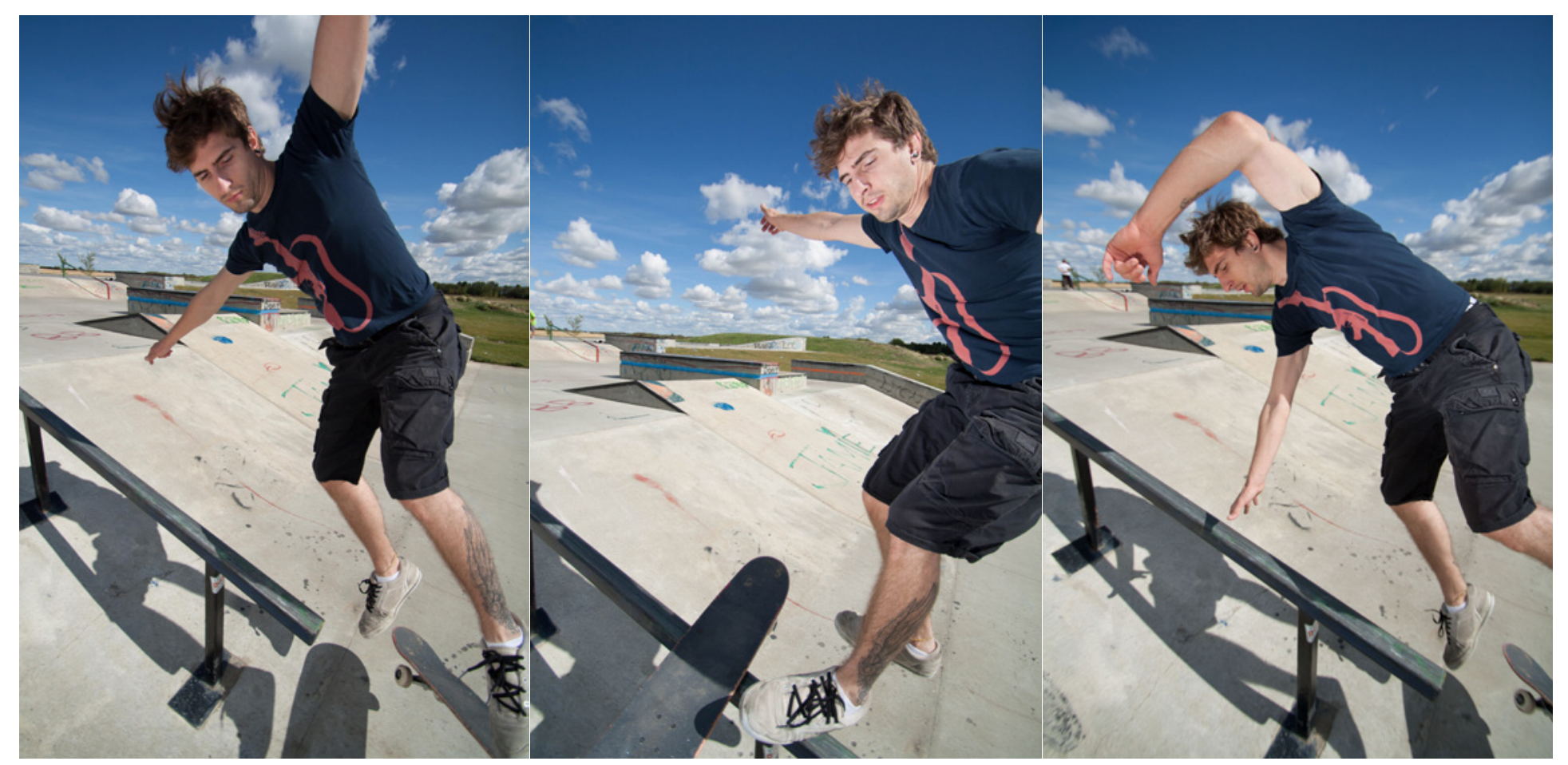

Figure 7: A skateboarder repeatedly attempting a Boardslide. It is not uncommon for a manouever to take a dozen attempts, even when the skateboarder has performed it before.

concrete reality and not something done strictly for recreation. ${ }^{44}$ Therefore, each successfully completed maneuver is seen as a triumph over adversity, a successful negotiation of the board-body-terrain relationship where the skateboarder has both tried and been tried.

$44 \quad$ lbid, 202. 
Figure 8: A Skaters' Eye diagram showing how a skateboarder perceives space,

focusing on the edge condition and two different trajectories through it.

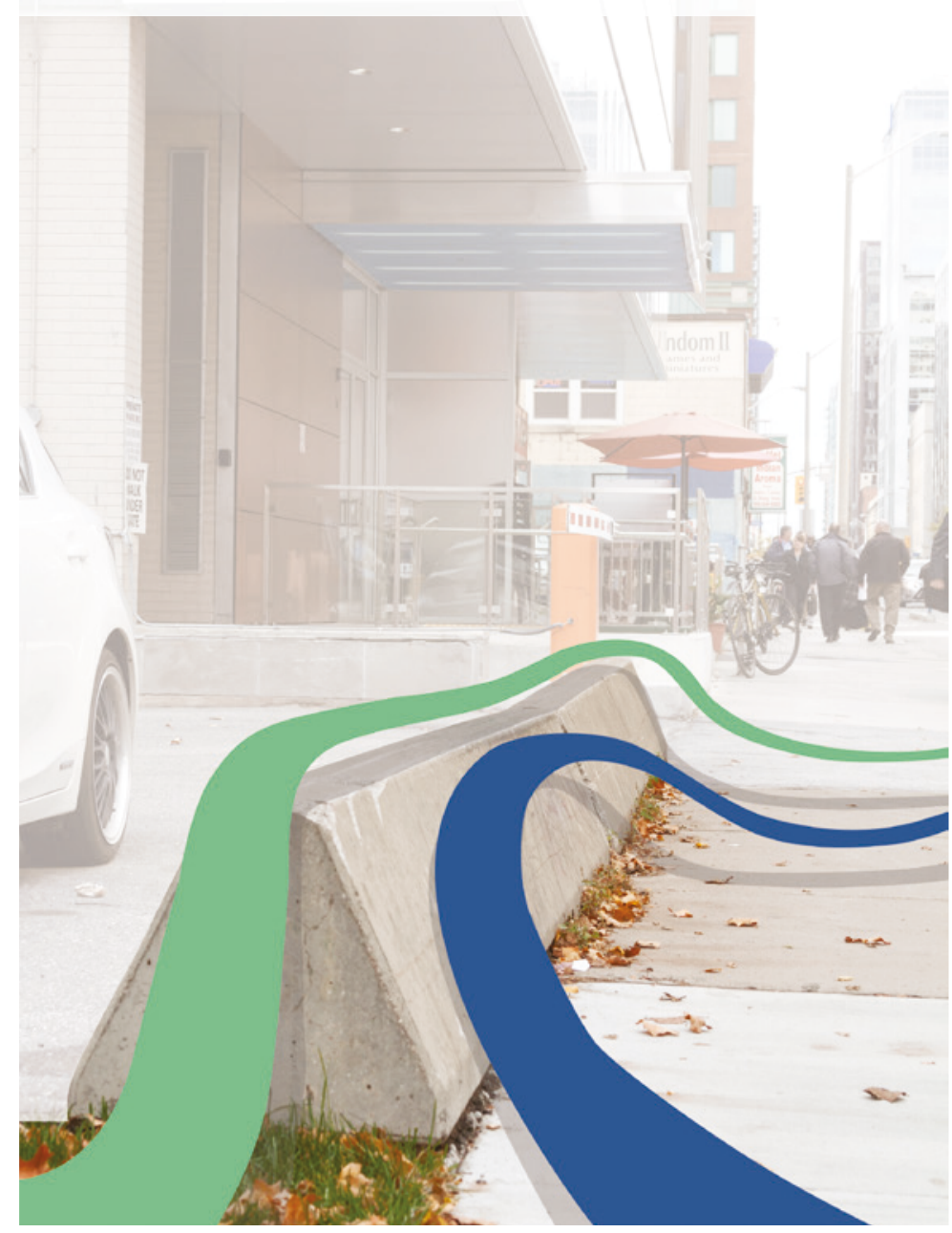

The ability of an activity or event to shape our world-view is not something that should be out of the ordinary for architects and designers; as it is, we too see the world differently than your average urbanite. And while it can be said that a whole range of activities can have similar worldshaping potential, the reason we are discussing skateboarders and not tennis players, for example, is that skateboarding provides something

that architects and designers 
understand and are accustomed to: criticism. Skateboarders are out, actively engaging in criticism of the built environment by putting use value over "the processes of exchange and consumption" which generally has precedent in the modern city. ${ }^{45}$ As Dr. Borden points out, skateboarders take the utilitarian objects of the city and form their critique of these objects by inscribing action on them. ${ }^{46}$ The parking block (figure 8) on its own signifies a boundary condition, delineating the strictly functional from the rest of the city. Skateboarders approach this as an obstacle and turn its meaning on its head. The edge condition becomes the central focus, inscribed with action and creative energy, now separated from its utilitarian intent.

$45 \quad$ Borden, Skateboarding... 237.

$46 \quad$ bid, 191-92. 


\section{[On Skateboarding: Misconceptions and Opportunities]}

It seems pertinent, having just discussed the risks associated with skateboarding, to take a moment and dispel some commonly-held misconceptions about skateboarding: mainly, "skateboarding is too dangerous" and "skateboarders are drunks and drug users." The latter misconception is the most straightforward to address and, in turn, dismiss. For her PHD dissertation at Kent state University in 2011, Judith A. Johns completed a study of 124 male skateboarders and their substance use. ${ }^{47}$ Dr. Johns set out to test the "Routine Activity Theory," which suggests that problem behaviors, such as substance use, are more a result of situations rather than the individual. As such, activities combining "(a) socializing with peers, (b) freedom from adult supervision, and (c) a lack of structure" resulted in

$47 \quad$ Johns, Judith $A$. "The relationship between involvement in unstructured unsupervised leisure and substance use in a cohort of adolescent male skateboarders." Electronic Thesis or Dissertation. Kent State University, 2011.

https://etd.ohiolink.edu/ 
higher instances of problem behavior. ${ }^{48}$ Upon completion, however, Dr. Johns found that skateboarders are no more likely to engage in substance use than their peers:

No statistically significant relationship was found between skateboarding and substance use. Most importantly, the findings of this study did not support the supposition that involvement in skateboarding was associated with substance use, as the theoretical and evidentiary literature suggests. ${ }^{49}$

The misconception that "skateboarding is dangerous" requires that the risk associated with skateboarding be approached from two different directions; first, skateboarding is actually less dangerous than several mainstream sports. Published in The Journal of Trauma Injury, Infection, and Critical Care, "Skateboard-Associated Injuries: Participation-Based Estimates and Injury Characteristics" was the first study to relate skateboarding and

48 Johns, "The relationship between..." 15.

49 Ibid, 221. 
other sports injuries with participation rates. ${ }^{50}$ The study found that the number of skateboard-related injuries that required emergency department treatment was 8.9 injuries per 1,000 participants, which is less than half the injury rate of both basketball and football with 21.2 and 20.7 injuries per 1,000 participants respectively. ${ }^{51}$ This puts the number of skateboardrelated injuries per 1,000 just under that of bicycling (11.5 per 1,000 participants), although it is interesting to note that in instances requiring hospitalization, including inter-hospital transfers and dead-on-arrival cases, bicycling has a rate of injury twice as high as skateboarding. ${ }^{52}$ While there is most certainly risk involved in skateboarding, the study finds that

50 Kyle, Susan B., Michael L. Nance, George W. Rutherford Jr., and Flaura K. Winston.

"Skateboard-Associated Injuries: Participation-Based Estimates and Injury Characteristics." The Journal of Trauma Injury, Infection, and Critical Care. 53 (2002): 686-90.

$51 \quad$ bid, 688.

$52 \quad$ Ibid 


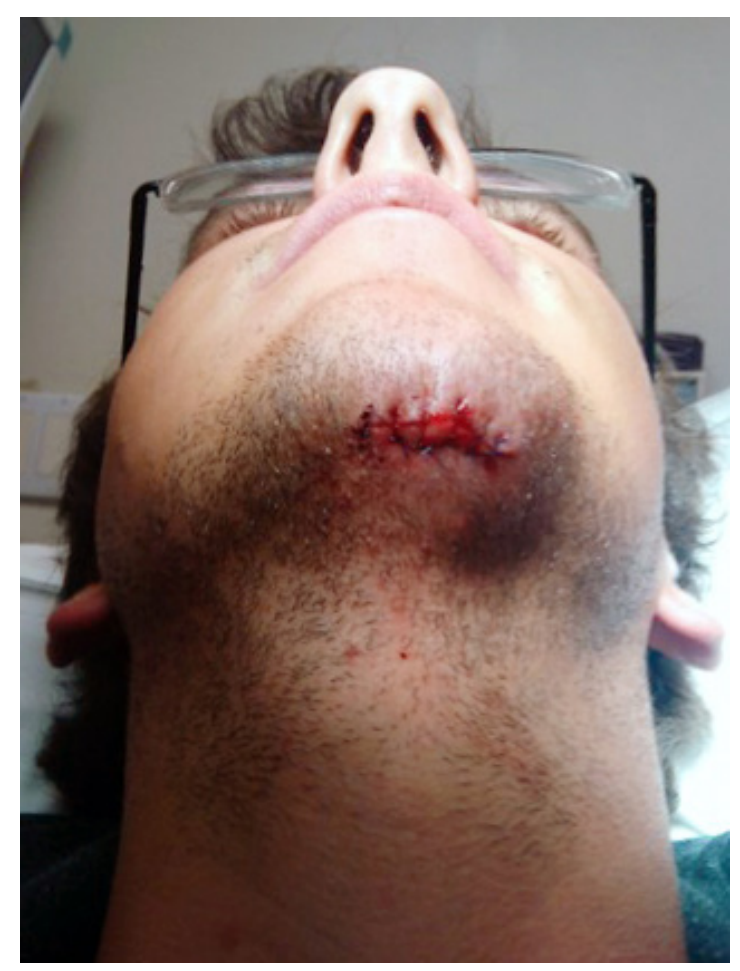

Figure 9: Statistically speaking, only 1 in 5618 skateboard related injuries are facial lacerations such as this. overall, "skateboarding is a comparatively safe sport." 53

The second method to challenge the "skateboarding is dangerous" attitude is to acknowledge the risk and realize that, to a certain extent, risk can be a good thing. As mentioned previously, skateboarding offers an opportunity to negotiate the inherent risk and push the limits, both of skateboarders' bodies and of the terrain. Catharine Ward Thompson goes into detail discussing common biases against teenagers and young people (collectively referred to as youth henceforth),

Kyle et al, "Skateboarding-Associated..." 689. 
citing that even their mere presence in public space is perceived as negative. ${ }^{54}$ The reason for this appears to be youths' attempts to "establish their self-identity" and unfortunately this often "conflicts with notions of ownership, control and responsibility expressed by managers and other people in control."55 Mrs. Ward Thompson cites teenagers', in particular, need to "explore and challenge boundaries (in every sense) as they go through adolescence and approach adulthood" as part of the process of establishing self-identity. ${ }^{56}$ Included in this is the desire to "test their physical skills, to take risks and learn about the way their bodies react with the environment."57 Skateboarding and the risk associated with it can, therefore,

\footnotetext{
$54 \quad$ Thompson, Catharine Ward. "Places to be wild in nature." In Urban Wildscapes. ed Anna Jorgensen and Richard Keenan London: Routledge, 2012. 51.

$55 \quad$ bid, 51

$56 \quad$ bid, 52

$57 \quad$ bid.
} 
be seen as part of the larger process by which youth grow, develop, and transition into adulthood.

The repercussions of this are much broader than they may initially appear. Researchers are now citing what is known as 'cultural autism,' "where a real, physical, sensual, direct bodily engagement with the natural world is replaced by a secondary, vicarious, distorted experience [...] often oneway, derived from television and other electronic media."58 This can be seen as the result of a society which is both risk-adverse as well as generally antipathetic to youth, as previously discussed. ${ }^{59}$ Having access to areas that allow for physical engagement, along with the making and breaking of things - without it being immediately perceived as vandalism - have been found to be vitally important to personal development and unfortunately

$58 \quad$ Thompson, Catharine Ward. "Places to be wild..." 56.

$59 \quad$ Ibid, 58 . 
these places are "increasingly difficult to access in today"s society."60 A British study published in 2007 demonstrated that one of the consequences of children having less access to this type of "experiential play" is reduced cognitive and conceptual development; "11- and 12-year-old children have been demonstrated to be between two and three years behind their counterparts 15 years ago," which is noted to have potentially significant implications for later generations. ${ }^{61}$ The way in which skateboarding engages both the body and the built environment can then be seen as one tool to counter cultural autism and have a beneficial impact on certain aspects of personal development. In later chapters, the emergence of the 'Do-It-Yourself' skate park movement can also be linked back to the need for both making and breaking during adolescence.

$60 \quad$ Thompson, Catharine Ward. "Places to be wild..." 57.

61 lbid, 60


Aside from skateboarding's clear and considerable potential as a tool for assisting in psychosocial development, there is also an important humanitarian potential that merits discussion. Mrs. Ward Thompson noted that the aforementioned "flexible or loose-fit spaces" that accommodate youth are doubly important because they "can often provide important places of escape for people with troubled childhoods, as well as for age groups or social or ethnic groups," who also find themselves unwelcome in more tightly controlled spaces. ${ }^{62}$ One such example of how skateboarding can be used to the benefit of these marginalized groups is found in the work of Skateistan, an international non-profit organization. ${ }^{63}$ Founded by Oliver Percovich, an American skateboarder who moved to Kabul, Afghanistan in 2007, Skateistan now operates four facilities, two in Afghanistan and two in Cambodia. ${ }^{64}$ Skateistan

62 Thompson, Catharine Ward. "Places to be wild..." 54.

63 "Skateistan | Skateboard NGO for children in Afghanistan, Cambodia." Skateistan. http://www.skateistan.org/ (accessed March 18, 2014).

64 McConnell, Fred. "Skate park and classrooms for 1,000 children in Mazar-e-Sharif." theguardian.com. http://www.theguardian.com/world/2014/mar/06/-sp-a-skatepark- 


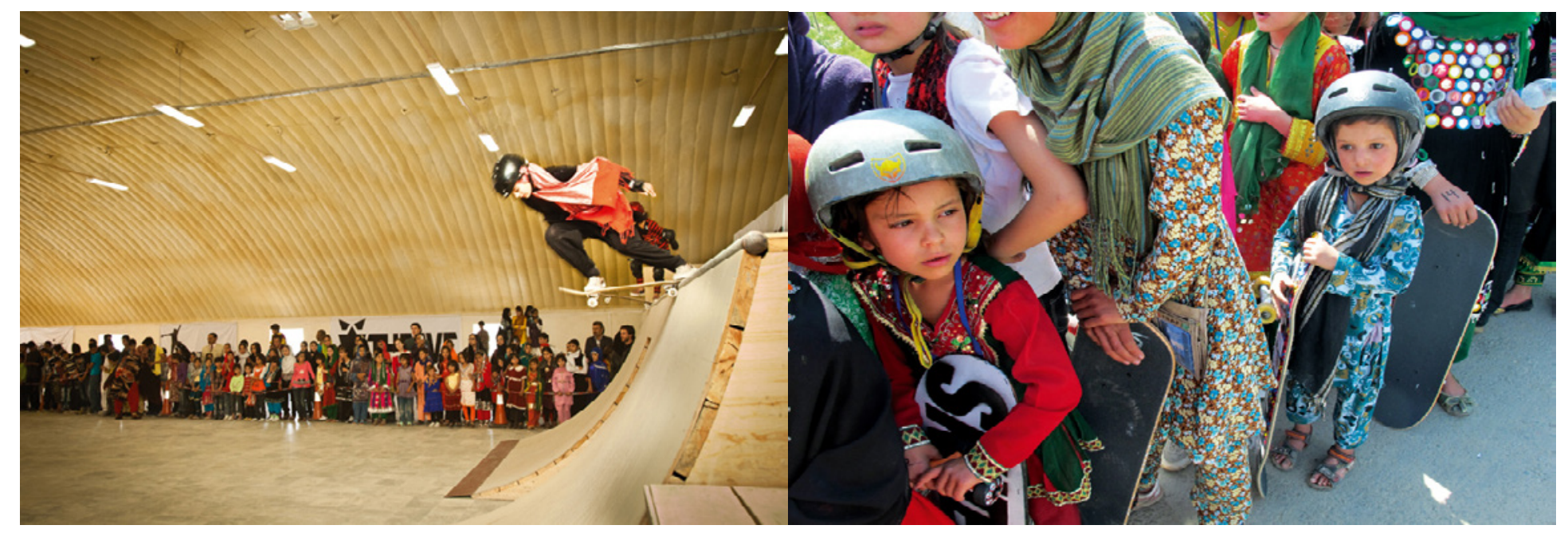

Figure 10.1 \& 10.2: Skateistan uses the draw of skateboarding to offer marginalized Afghans access to education and skills training.

uses the "hook" of skateboarding to encourage and provide opportunities for "education, leadership, and creative thinking that help break the cycles of poverty and exclusion."65 Students range in age from $5-18$ years old and approximately 50\% of the students are street-working children. ${ }^{66}$ Of particular importance is that skateistan is working hard to empower

and-classrooms-for-1000-children-in-mazar-e-sharif\#comments (accessed March 18, 2014).

65 "What we do." Skateistan. http://www.skateistan.org/programs (accessed March 18, 2014).

66 "About Us." Skateistan. http://www.skateistan.org/content/our-story (accessed March 18, 2014). 
Afghan women. In Afghanistan, boys and girls are segregated after the age of 12. To encourage girls to participate in skateboarding, skateistan built an indoor facility to host female-only classes taught by Afghan women. ${ }^{67}$ Precisely as Mrs. Ward Thompson described, skateboarding provides a place for people of different gender, age, social, ethnic and economic groups to come together and have a positive experience.

67 Carter, Beth. "Spreading Joy in Afghanistan and Cambodia, One Skateboard at a Time." Wired.com. http://www.wired.com/playbook/2012/11/skateistan-2 (accessed March 18, 2014). 


\section{[Case Studies]}

As mentioned previously, it is common for people to hold very reductive views of both skateboarding and skateboarders. To help alleviate this, it would now be useful to provide a few case studies illustrating real world examples of how skateboarders have had a positive effect on their environments. These case studies serve to demonstrate skateboarders' influence on underutilized space, through both appropriation of an existing architectural space, and conversely through the transformation of urban infrastructure into skateable space. 


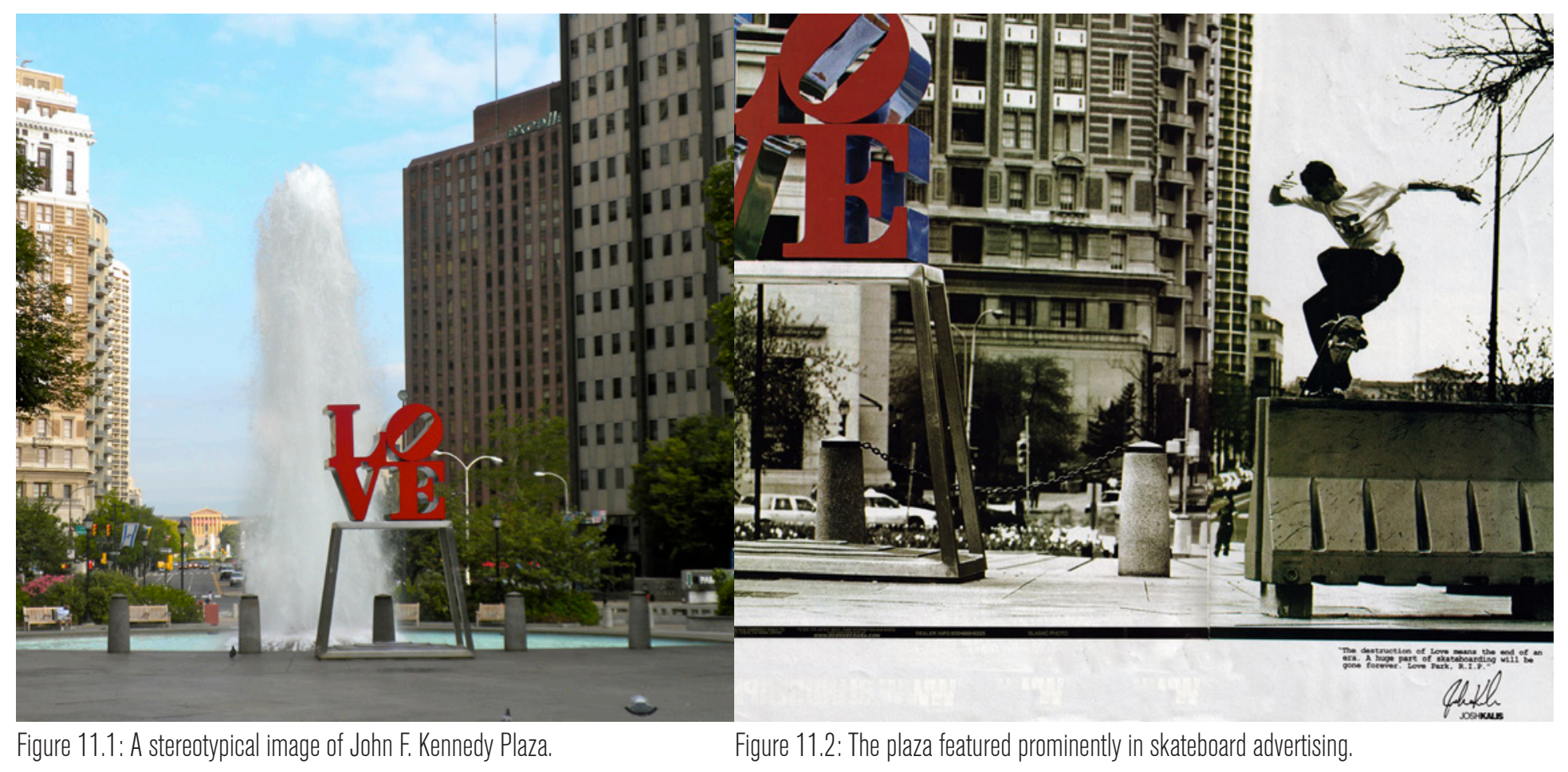

[Case Study: John F. Kennedy Plaza]

John F. Kennedy Plaza - better known as LOVE Park - is located in the city center of Philadelphia, Pennsylvania and was completed in 1965. The park's original plan was part of Edmund Bacon's thesis from Cornell University 
but the design and detailing of the park was completed by Vincent Kling as Bacon was then head of the city's planning commission. ${ }^{6}$ Initially, the plaza was well received and a favorite spot to eat lunch with the local office workers. By the late 1980s, however, the park was overrun by homeless people, drug addicts and the day-to-day activities revolving around druguse, pan-handling, the public display of biological expulsions and conflict. ${ }^{69}$ Despite this, LOVE Park became a world-famous skateboard spot, appearing in countless magazines and publications around the world, even becoming a playable level in popular skateboard video games. ${ }^{70}$ With the skyrocketing popularity of LOVE Park and the return of office workers and pedestrians, the city of Philadelphia decided in 2002 that the only issue with the park

68 Edmund Bacon, Interview. Love Story: The Saga of a Skateboard Landmark (Web Video, 2004) Accessed December 02, 2012 http://vimeo.com/866431

69 Ocean Howell, “The 'Creative Class' and the Gentrifying City: Skateboarding in Philadelphia's Love Park," The Journal of Architectural Education (2005); 33-34.

$70 \quad$ lbid, 34 
was all the skateboarders and undertook official renovations to make the park un-skateable. ${ }^{71}$ This was a devastating blow to the skateboard community in Philadelphia and was felt in the wider skateboard world. There were, of course, public outcries from skateboarders, but also from the larger community including Philadelphia City Councilors, businesses, and even Edmond Bacon and Vincent Kling. ${ }^{72}$ In an attempt to appease the main proponent of the skateboard ban (then-Mayor John F. Street), skateboard shoe manufacturer DC offered the city \$1 million over 10 years to "pay for the maintenance, security, upkeep and replacement of obstacles due to skateboarding in the park." 73

$71 \quad$ Howell, "The 'Creative Class"' 34.

$72 \quad$ Ibid, 34.

73 "DC Shoes gifts \$1 million to the city of Philadelphia in hopes of reopening LOVE Park to skateboarders" DC Shoes Inc. press release, June 1, 2004, on the Free LOVE Park website, http://www.ushistory.org/lovepark/media/dcshoes.htm, accessed March 19, 2014. 


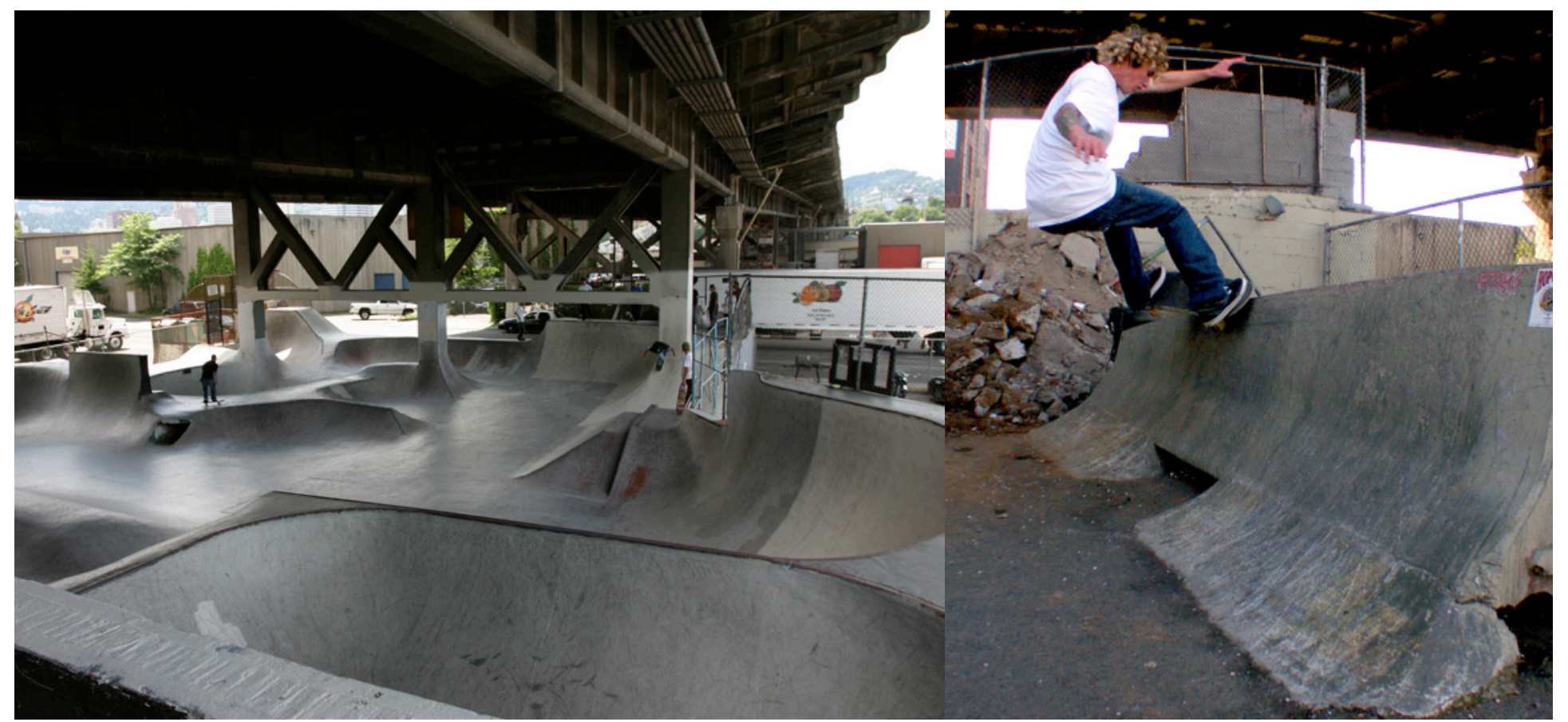

Figure 12.1: An overview of Burnside built around the bridge support structure.

Figure 12.2: A parking barricade turned obstacle.

\section{[Case Study: Burnside Skate Park]}

Started by a group of skateboarders in 1990, Burnside Skate Park began as a few bags of concrete mixed with water from surrounding puddles to create a small 
transition underneath Portland's I-95. ${ }^{74}$ From that, Burnside grew using "found and donated construction materials molded through the untrained use of rudimentary tools such as shovels and pickaxes."75 It is now regarded as the most famous and significant 'Do-It-Yourself' skateboard park in the world, precipitating an explosion of other D.I.Y. parks internationally. ${ }^{76}$ For almost 25 years now, Burnside has existed and grown not through prescribed planning but through "ad hoc use modifications" as an "open-ended do-ityourself collaboration". ${ }^{77}$ While starting out, the park was an illegal occupation of city property. Today, the park is officially sanctioned by the city of Portland, covering approximately 10,000 square feet. ${ }^{78}$ During

$74 \quad$ Under the Bridge. Film. Directed by Jake Phelps. San Francisco, CA: High Speed Productions, 2010.

75 Vivoni, F. "Spots Of Spatial Desire: Skateparks, Skateplazas, And Urban Politics." Journal of Sport \& Social Issues 33, no. 2 (2009): 137

76 Eisenhour, Mackenzie. 2012. "10 DIV SPOTS." Transworld Skateboarding 30, no. 3: 032. MasterFlLE Premier, EBSCOhost (accessed November 24, 2013).

77 Vivoni, F. "Spots Of Spatial Desire..." 130-149.

78 Hupp, Dave. "Burnside History." The Burnside Project. http://www.burnsideproject.blogspot.ca/ (accessed December 14, 2013). 
Burnsides' transition from illegal appropriation to sanctioned space, City

Councilors "admired the skaters' 'just do it' attitude."79 Part of the reason that Burnside was accepted by local residents and Council was that police noticed a significant drop in car theft and robberies from the surrounding community. ${ }^{80}$ Due to the success and popularity of the space, along with the previously mentioned LOVE Park, they eventually became playable levels in Tony Hawks' video game franchise which sold over 30 million units worldwide. ${ }^{81}$ This only served to increase their renown as skateboarding Meccas, drawing in skate-tourists from all over the globe.

$79 \quad$ New York Times, "Homemade Skate Park," November 13, 1994.

http://www.nytimes.com/1994/11/13/magazine/sunday-november-13-1994-homemadeskate-park.html(accessed March 19, 2014).

80 Howell, 0.. "Skate park As Neoliberal Playground: Urban Governance, Recreation Space, And The Cultivation Of Personal Responsibility." Space and Culture 11, no. 4 (2008): 485.

81 Iwata, Edward. "Executive Suite: Tony Hawk leaps to top of financial empire." USA Today, March 9, 2008. http://usatoday30.usatoday.com/money/companies/ management/2008-03-09-tony-hawk-entrepreneur_N.htm (accessed December 14, 2013). 


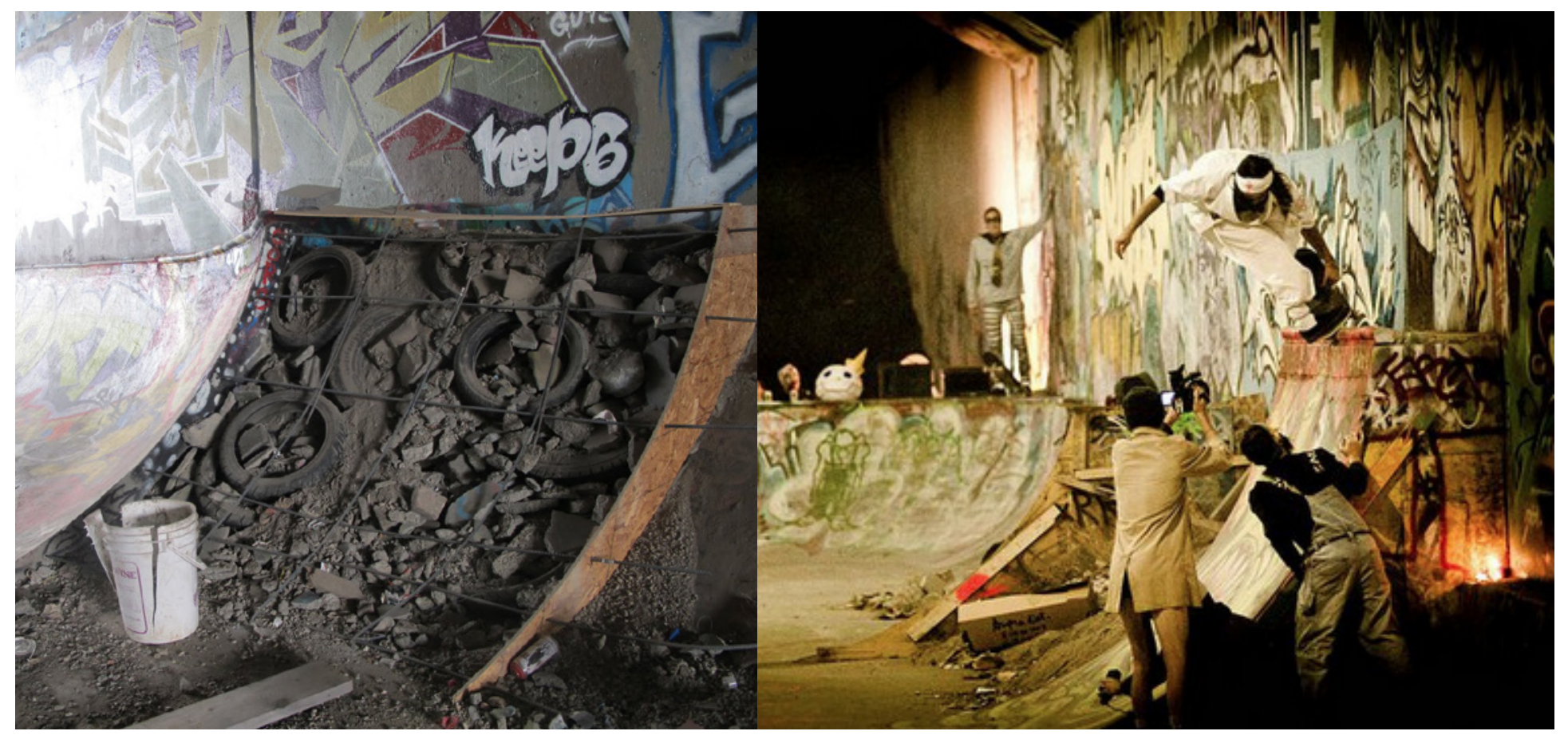

Figure 13.1: Tires and rubble serving as infill prior to a cement pour.

Figure 13.2 One such rubble and concrete ramp in use.

\section{[Case Study: Leeside Skate Park]}

A direct descendant of the Burnside D.I.Y. attitude and the most prominent example of skateboarders' large-scale appropriation of space in Canada is Leeside Memorial Skate Park in Vancouver. Dedicated to murdered artist and 
skateboarder Lee Matasi, Leeside was once a tunnel intended to form part of a Vancouver transit loop but was forgotten by the city in the early 1990s and appropriated by Mr. Matasi and his friends as a place to skateboard and paint when it was raining. ${ }^{82}$ Initial conflict with local authorities included having the park entirely buried by the city engineering department, only to be dug out by hand over the course of two years by Leeside locals. ${ }^{83}$ Today, the park is a hub for the community, hosting events in addition to providing a place to skateboard, and is officially sanctioned by the City of Vancouver. ${ }^{84}$ Again, like Burnside, Leeside was entirely built, financed and cared for by locals who raised $\$ 25,000$ to perform an overhaul and upgrade of

82 Robinson, Matthew. "Leeside Skate Park, Lee's Domain." The Tyee. http://thetyee.ca/ News/2011/09/28/Leeside-Skate-Park/ (accessed December 14, 2013).

$83 \quad$ bid.

84 "Leeside Tunnel skateboard park." City of Vancouver Official Website. https:// vancouver.ca/parks-recreation-culture/leeside-tunnel-skateboard-park.aspx (accessed March 19, 2014). 
the space. ${ }^{85}$ Unfortunately, while in the process of completing the upgrade, arsonists broke into the site and caused significant damage to the park. ${ }^{86}$ While initially concerned that the city and local police would use the skateboarders as a scapegoat and permanently close Leeside, the Vancouver Police Department went on record saying the fire was, in fact, the work of arsonists and released a surveillance video seeking the publics' help in identifying the perpetrators. ${ }^{87}$ At the time of writing - just over a month after the fire - the community has already hosted a number of fundraising events to help pay for the necessary repairs to the skate park. ${ }^{88}$

85 Meiszner, Peter. "Police release surveillance video after vandals destroy East Vancouver skate park." Global News. http://globalnews.ca/news/1107682/1107682/ (accessed March 19, 2014).

86 Ibid.

87 CBC News. "Skate park arsonist caught on camera? VPD releases video - British Columbia - CBC News." CBC News British Columbia. http://www.cbc.ca/news/canada/britishcolumbia/skatepark-arsonist-caught-on-camera-vpd-releases-video-1.2515802 (accessed March 19, 2014).

88 "LEESIDE FUNDRAISER 3/3 at astorio's sunday... - Antisocial Skateboard Shop." Antisocial Skateboard Shop. http://antisocialshop.com/post/78184984456/leeside fundraiser-3-3-at-astorios-sunday (accessed March 19, 2014). 


\section{[Case Study: Conclusions]}

The preceding case studies have clearly demonstrated real-world examples of how skateboarding can have significantly beneficial impacts on space, the community and the users. These case studies demonstrate what has been circulating in professional public management literature and from local news outlets for years: "the presence of skateboarders can deter vandalism, drug use, prostitution, and homeless encampments - skateboarders provide 'eyes on the street.'"89 As in the case of LOVE Park, skateboarders can sometimes be too adept at promoting urban renewal and, having no other group to

$89 \quad$ Howell, 0.. "Skate park As Neoliberal..." 485. 
dissuade, become the target of persecution by local authorities themselves. The D.I.Y. nature of both Burnside and Leeside has been doubly beneficial as the construction relies on discarded or surplus building materials which otherwise would have found their way into a landfill as trash. All three case studies have proved to bring a real and tangible benefit to their community without the use of public funds. 


\section{[On Skateboarding: Core Concepts]}

Having gone into great detail over the course of this writing to initiate the reader into the world of skateboarding and all that it entails, there now exists a need for brevity. In order to continue as effectively as possible, the skateboarders' world-view will be boiled down to a few key concepts:

1. Architecture is not passive. Skateboarding is both effected and affected by the architecture of the city.

2. Skateboarders have a more fully engaged experience of the city. Utilizing vision, touch, and sound as well as different rhythms and cycles, they bring life and activity to spaces outside of regular business hours. 
3. Skateboarding is a negotiation, not a binary action. It is a constant challenge to moderate, as Dr. Borden explains, the "body-board-terrain" relationship.

4. Skateboarders understand space at both micro and macro scales: the micro stemming from the relation of board and body; the macro stemming from the understanding of the body in relation to the city.

5. Skateboarders understand skateboarding as a subculture, more so than merely a sport. As such, they operate with a certain level of seriousness. This has to do with the fact that failure rates are high, perhaps higher than any other sport, and with each attempt they are putting themselves in physical danger. 


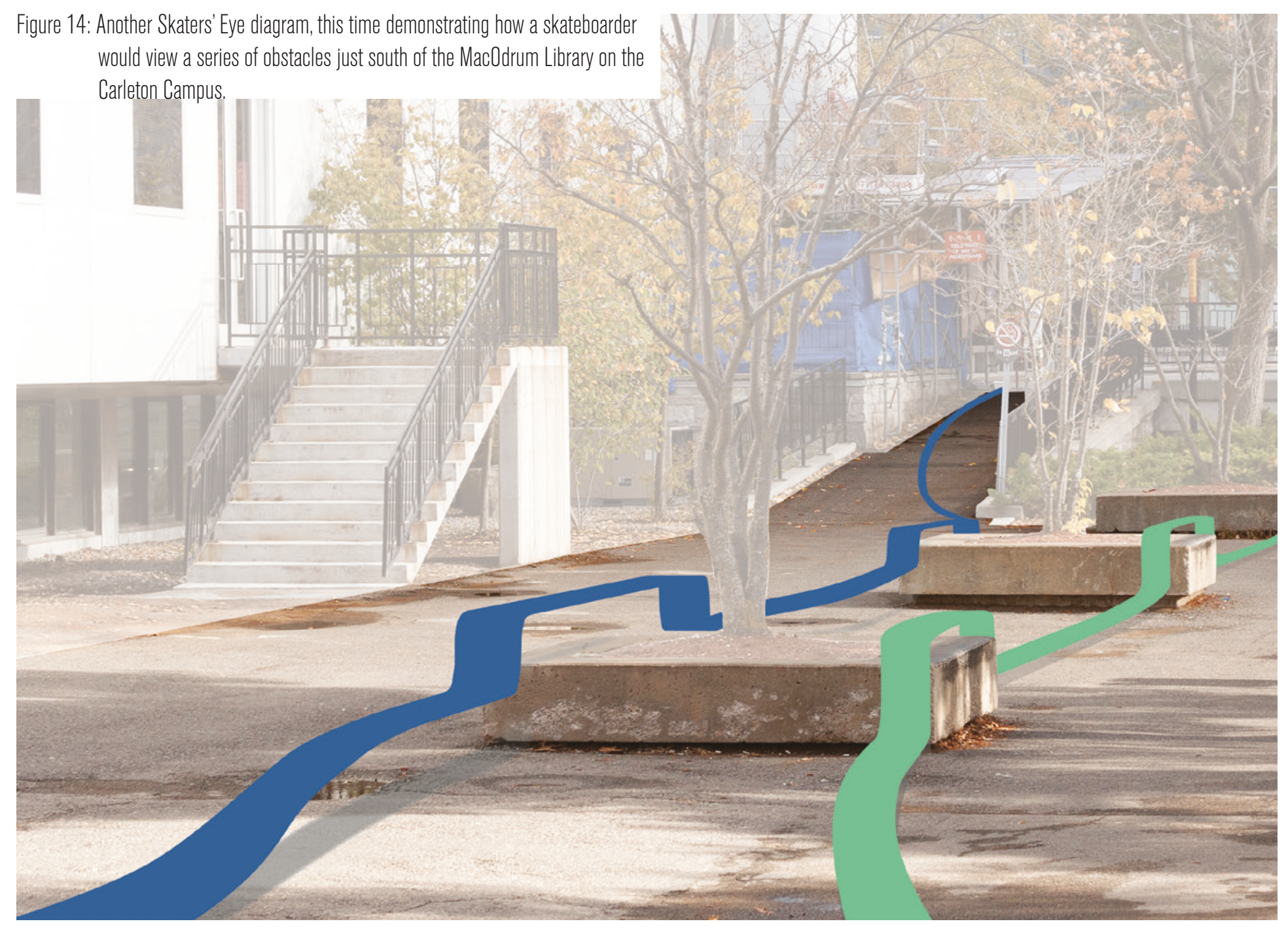


Approaching the City of Ottawa from the point of view of both an outsider and a skateboarder, Chaudière Island is immediately interesting. The Booth Board Mill in particular is worth noting, with its metropolitan setting, massive concrete façade, blocked-in windows and limited access - but as the graffiti points out, there is most certainly access. While its island location, among other things, make it impractical for appropriation as a skateboard park, it does provide a perfect opportunity to try and implement some aspects of skateboarding's architectural considerations that were just laid out. 


\section{[Chaudière Island: A History]}

By the time Samuel de Champlain had provided the first written account of the Chaudière Falls in 161390, First Nations people had been using the falls for mellenia. ${ }^{91}$ Just prior to the widespread takeover of the area by the timber trade, the base of the Chaudière Falls had been used as a place for gatherings, trade and religious ceremonies by the Algonquin people. ${ }^{92}$ The name Chaudière, or "boiler," actually comes from the Algonquin name for the falls: Asticou, or "the kettle," which described how the water was so agitated by the waterfalls and rapids that it appeared to boil as if it were hot. ${ }^{93}$ While the link between the fur trade and early Canadian history is well known, timber production has also played a significant role, especially go Woods, Shirley E.. Ottawa, the capital of Canada. Toronto: Doubleday Canada, 1980, 6.

91 Bassett, Shannon. "Logjammed." Canadian Architect, January 1, 2007. http://www.canadianarchitect.com/news/logjammed/1000209839/ (accessed November 17, 2013).

92 Ottawa Citizen. "Chaudière Falls at the heart of Ottawa's history." Ottawa Citizen, print.html?id=abc57a82-a4db-4069- $\quad$ 8fcc-1176949ea054(accessed March 4, 2013).

93 "Chaudière Falls at the heart of Ottawa's history." 
in the Ottawa Valley. Early in the 19th century, Philemon Wright founded the first timber mill in the area and began what would become 200 years of industrial use on the site ${ }^{94}$. In 1836, George Buchannan built a crib slide between Chaudière and Victoria Island - which also became a noted tourist attraction in addition to its industrial use. ${ }^{95}$ Indeed, all the lumber barons of Ottawa - Wright, Bronson, Booth, etc - gained their prominence from the timber trade on the Ottawa River. By $1892 \mathrm{~J} . \mathrm{R}$. Booth was running the largest timber operation in the world, manufacturing 140 million board feet per year, which "was more than double that of any major Ottawa valley firm [...] By 1900

94 Brandt, Mark. "National Treasure: The Chaudière District in Canada's Capital." Heritage Ottawa Newsletter 33, no. 2 (2006). http://heritageottawa.org/en/ national_treasure_chaudière_district_canada's_capital (accessed November 15, 2013).

See Also: Elliot, Bruce S.. "PHILEMON WRIGHT (1760-1839)." Up the Gatineau! 26 (2000). http://www.guhs.ca/publications/utga-philemon-wright.html (accessed November 15, 2013).

95 Mika, Nick, and Helma Mika. Bytown, the early days of Ottawa. Belleville, Ont: Mika Pub. Co., 1982. 121-22. 
all of the coastal mills in British Columbia were producing only 100 million feet annually."96 By 1905, the traditional lumber trade had reached its peak in the ottawa-Gatineau area and as a result, J.R. Booth purchased a site on Chaudière Island to begin pulp and paper production. This allowed him to make more effective use of softwood stores he previously would have sold. ${ }^{97}$ As time went on, Chaudière Island passed from Booth to the E.B. Eddy company and then to Domtar Inc. ${ }^{98}$

Today, the Booth Board Mill, Chaudière Island, and the surrounding

industrial lands are known collectively as the "Domtar Lands." Sandwiched

96 Benidickson, Jamie, "BOOTH, JOHN RUDOLPHUS,"

See Also: "Lumber." Trinity Western University - Laurentian Leadership Centre Heritage. http://twu.ca/sites/laurentian/heritage/lumber.html (accessed November 17, 2013)

97 Benidickson, "BOOTH, JOHN RUDOLPHUS"

98 The Canadian Manufacturer's Association. "Business and History - The E. B. Eddy Company." Western Libraries Company Information Canada. http://www.lib.uwo.ca/ programs/companyinformationcanada/ccc-ebeddy.html (accessed November 17, 2013).

And: "Domtar Won't Dictate Fate of Falls." The Ottawa Citizen, Jun 17, 1998 accessed

November 17, 2013. http://search.proquest.com/docview/240165831? ?accountid=9894. 


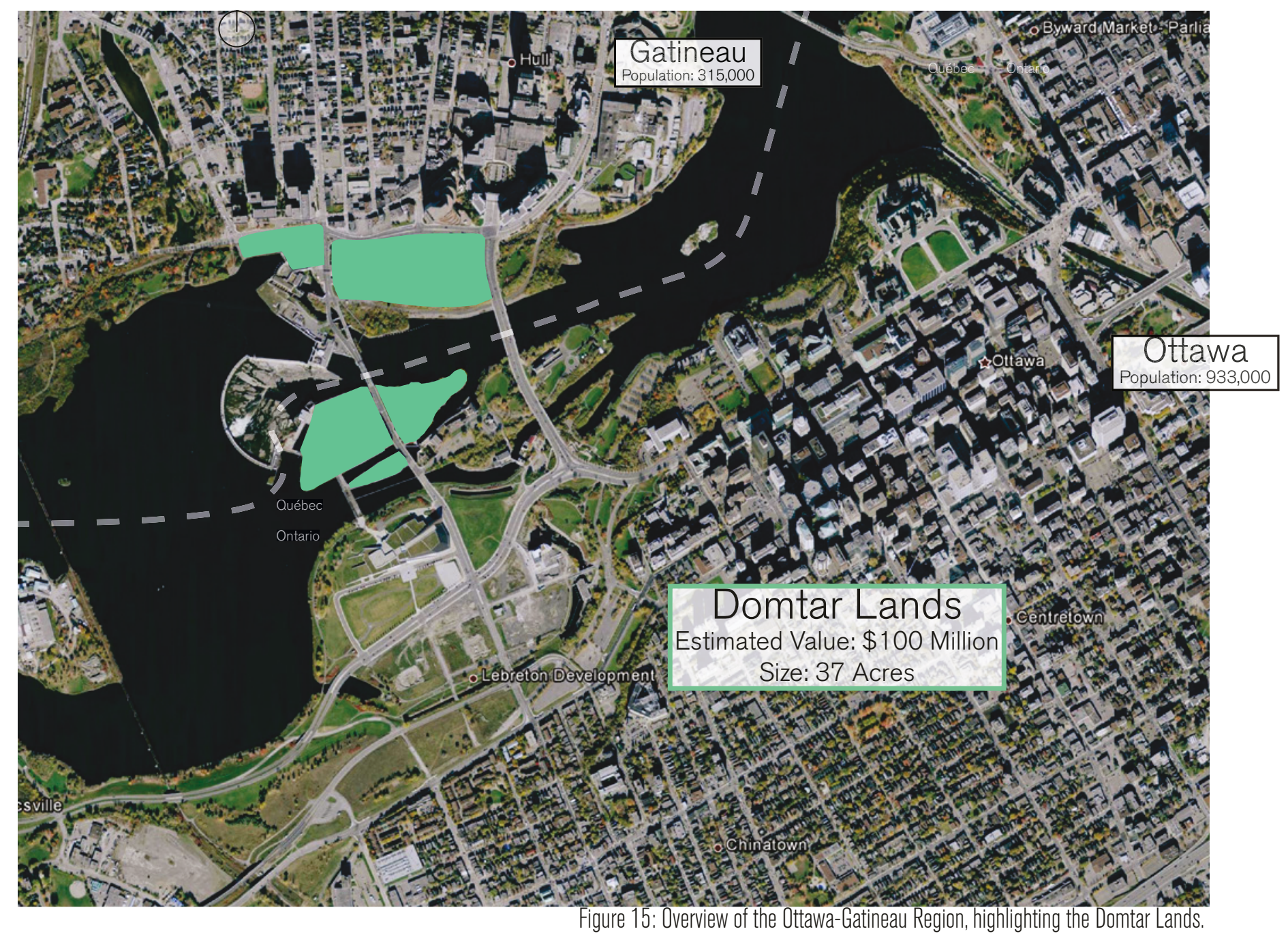


between Ottawa and Gatineau, the Domtar Lands cover 37 acres across three major landmasses and two provinces; their estimated value is around \$100 million or $\$ 2.7$ million per acre99. Originally built in 1912, only a potted history of The Booth Board Mill exists today. ${ }^{100}$. Architect Barry Padolsky provides the most accurate and complete account of the Booth Board Mill's history as he was hired by the National Capital Committee in 1984 to evaluate the building. Even the former Chief Architect for E.B. Eddy Limited - the owners of the Board Mill at the time of Mr. Padolsky's study - was unsure of the composition of some elements in the building's construction. ${ }^{101}$

$99 \quad$ Payne, Elizabeth. "Domtar buildings need heritage protection,architect says."

The Ottawa Citizen, July 29, 2013. http://www.ottawacitizen.com/news/ottawa/ Domtar+buildings+need+heritage + protection+architect+says/8722740/story.html (accessed September 21, 2013).

And: Oyelowo, Oyeyinka. "Fate of Chaudière property uncertain."Centretown News

(Ottawa), April 6,2012. http://wwww.centretownnews.ca/indexphp?option=com_ content\&task=view\&id=3167\&ltemid=113(accessed April 13, 2013).

100 Padolsky, Barry, "J.R. Booth Board Mill: Existing conditions and potential for future

$101 \quad$ bid. 9 public use,"Eriksson Padolsky Architects, December 1984, 11 
According to Mr. Padolsky, "The Booth Board Mill is loosely organized in one, two, and three storey blocks or 'buildings' on five distinct levels,"102 the configuration of which can be seen in the figure 17.4. Operations at the Booth Board Mill officially ceased in 1979. Mr. Padolsky outlined the difficulties in the adaptive re-use of this building, including the complexity of the interlocking structures; the sheer scale and volume of space to be occupied; and the extensive commitment required for the development ${ }^{103}$. At the time of his report, Mr. Padolsky expressed serious concern for the sustained health of the Board Mill. He stressed that the overall structure of the building appeared to be in sufficient enough condition to viably support adaptive re-use as long as appropriate measures were taken to prevent further deterioration ${ }^{104}$

\begin{tabular}{ll}
\hline 102 & Padolsky, "J.R. Booth..." 7 \\
103 & Ibid, 12 \\
104 & Ibid, 10.
\end{tabular}




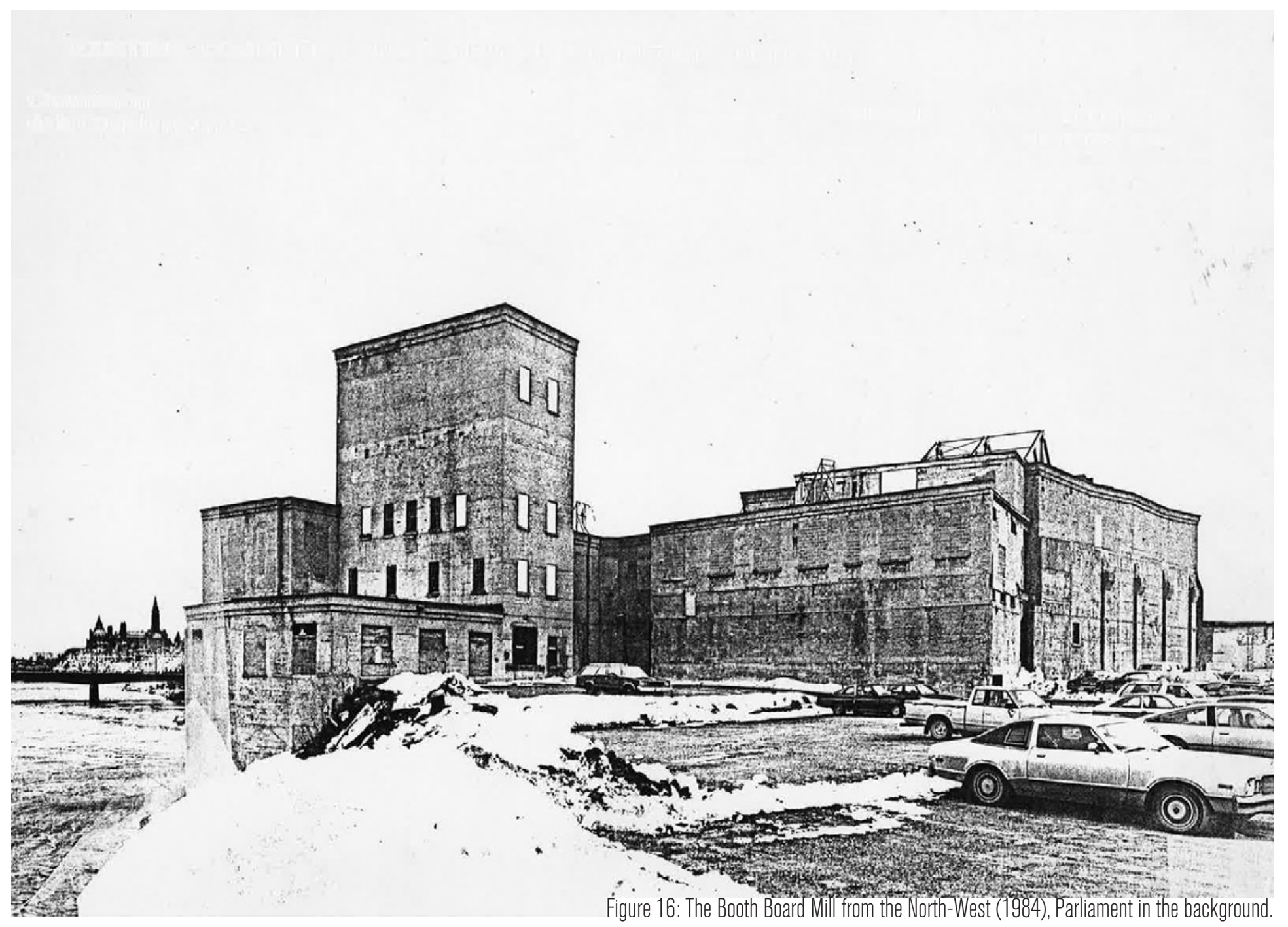




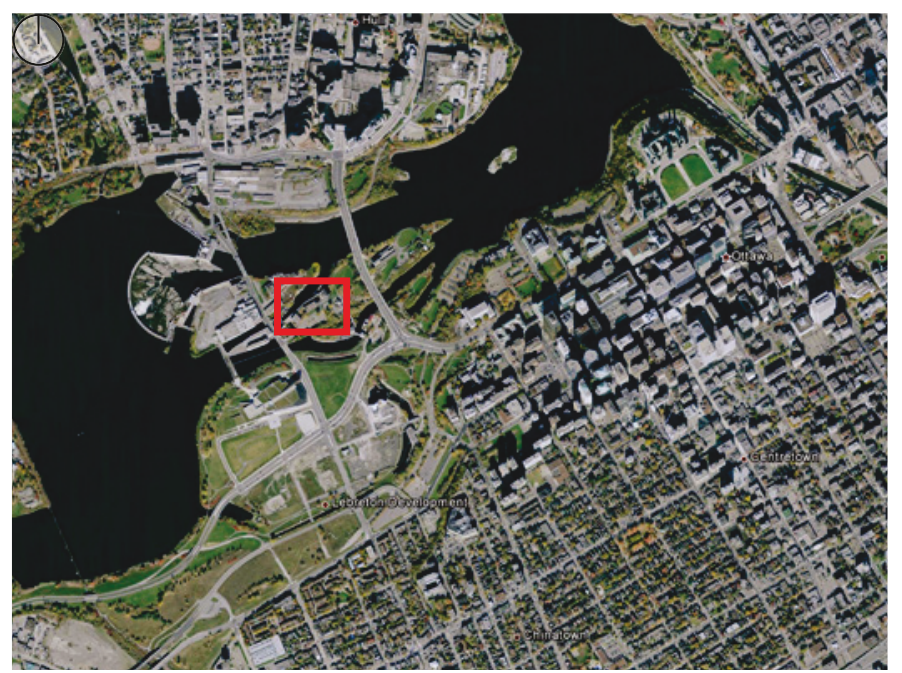

Figure 17.1: Ottawa, ON.

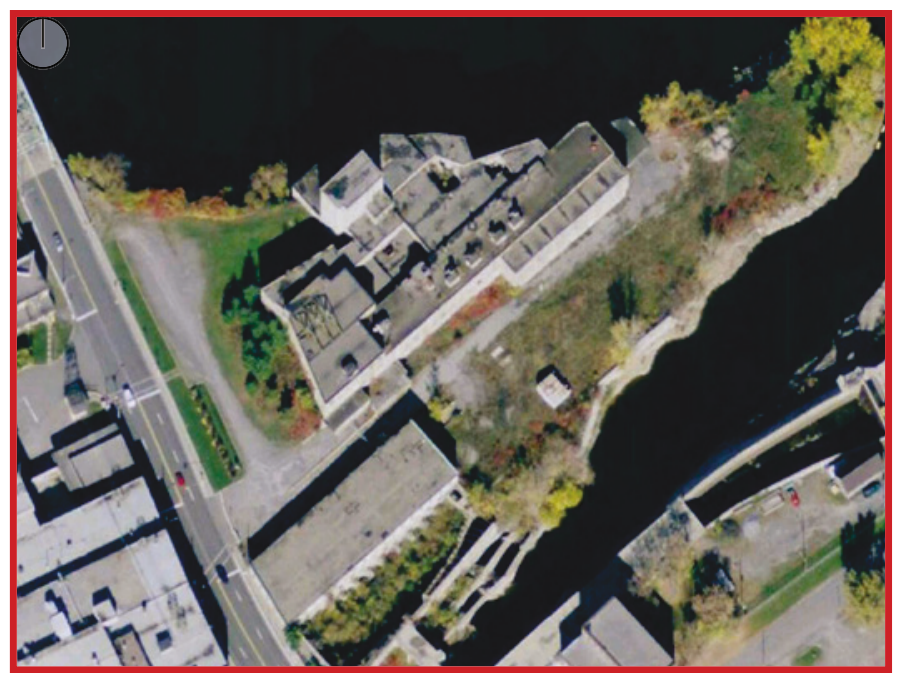

Figure 17.2: Chaudière Island.

The report on the Board Mill by Mr. Padolsky was actually just one part of a long line of inquisition by the National Capital Commission into the Domtar Lands. ${ }^{105}$ Following Mr. Padolsky's work in the 1980s, local architect Mark Brandt was hired by the N.C.C. in the 1990s and "has completed nearly 20 studies on the islands."106 Despite this, when Domtar officially shut down operations at the Chaudière facilities in 2007, the N.C.C. was unable to 105 Oyelowo, Oyeyinka. "Fate of Chaudière property uncertain." Centretown News (Ottawa), April 6, 2012. http://www.centretownnews.ca/index.php?option=com_ content\&task=view\&id=3167\&ltemid=113 (accessed April 13, 2013). 


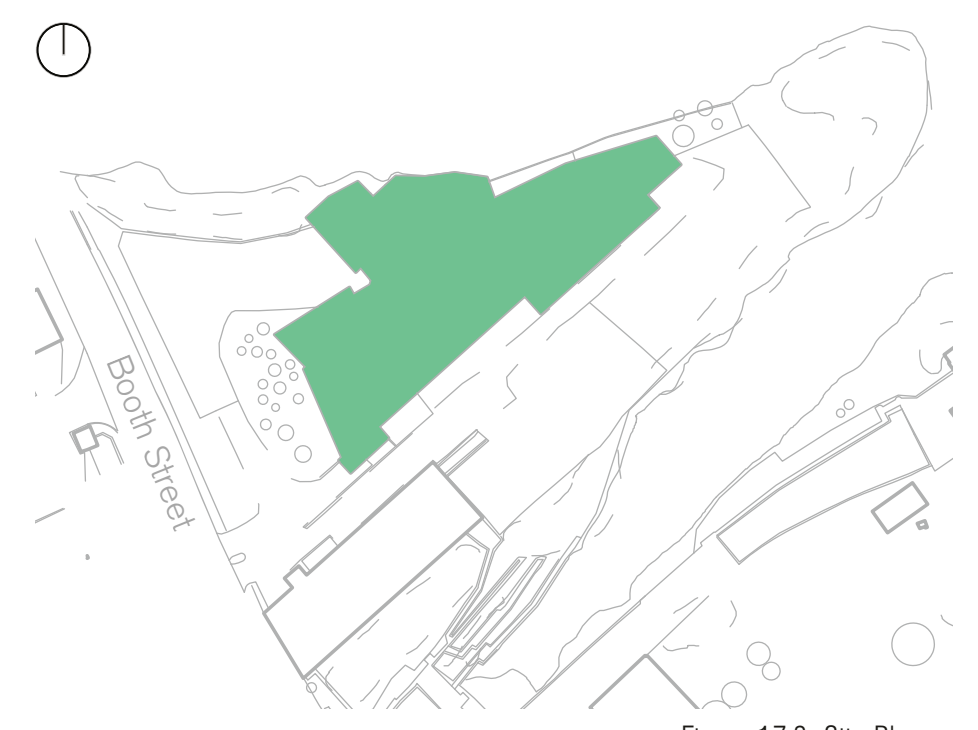

Figure 17.3: Site Plan.

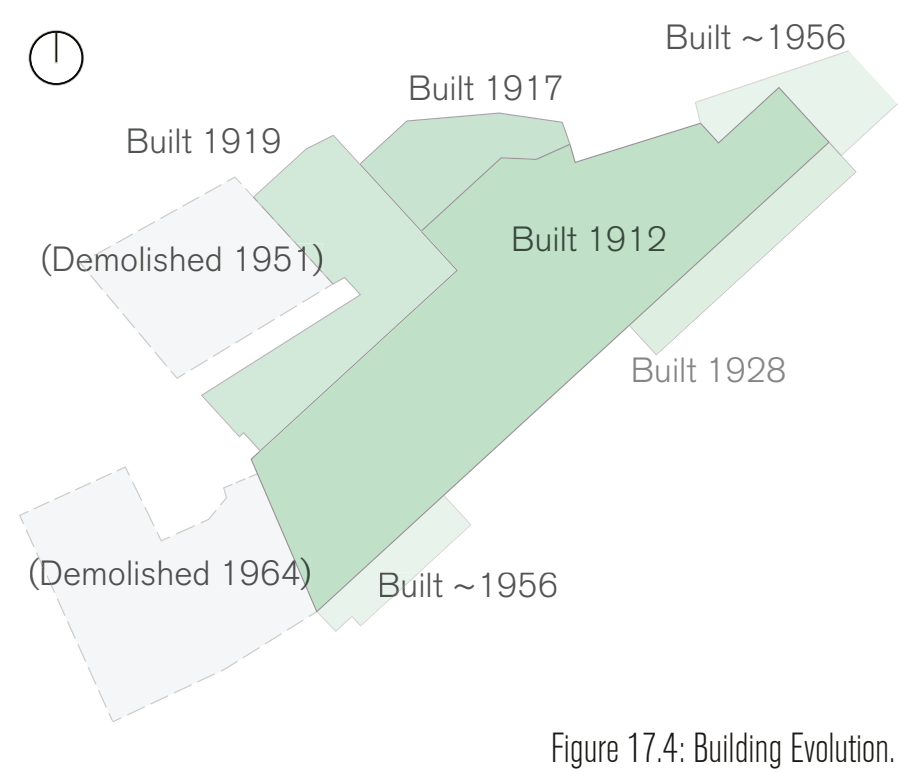

Figure 17.4: Building Evolution

bolster enough support to purchase the lands, despite the fact that the region maintains its "national interest" classification. ${ }^{107}$

Aside from the work done by the N.C.C., First Nations groups have also had a vested interest in the site as it was and remains a place of great historical and religious significance, despite its vast industrial

107 Payne, Elizabeth. "Domtar buildings need heritage protection, architect says." Ottawa Citizen, July 29, 2013.http://www.ottawacitizen.com/news/ottawa/ Domtar+buildings + need +heritage+protection+architect+says/8722740/story.html (accessed September 21, 2013). 
occupation. ${ }^{108}$ of particular interest is the work of Dr. William Commanda, Algonquin elder and Officer of the Order of Canada, and the proposal he put forth for Chaudière Island and surrounding area in 2007. ${ }^{109}$ The proposal is the result of years of work done by Dr. Commanda and a great number of collaborators, including architect Douglas Cardinal. ${ }^{110}$ The proposal presents a "bold-four-fold vision" including "Freeing the Chaudière Falls"; "Creating

a City Park \& Historic Interpretive Centre"; "Building a Peace Building Meeting Site"; and "Building an Aboriginal Centre."111 The proposal was intended to have a number of effects. Firstly, it would provide relief from

108 "Asinabka." Asinabka. http://www.asinabka.com/index.htm (accessed March 21, 2014).

See Also: "Welcome." Circle of All Nations.ca. http://www.circleofallnations.ca/Welcome.html (accessed March 21, 2014).

109 "PROPOSAL FOR A SPECIAL NATIONAL HISTORIC CENTRE AT ASINABKA/CHAUDIÈRE FALLS, OTTAWA, CANADA," Circle of All Nations press release, n.d. on the Asinabka website. http://www.asinabka.com/Marketing\%20Material/ASINABKABNbrochureFinalFrenchEng.pdf, accessed March 21, 2014.

110 "Asinabka / Victoria Island Documents." Asinabka. http://www.asinabka.com/documents. htm (accessed March 21, 2014).

111 "PROPOSAL FOR A SPECIAL..." 
urban sprawl by creating a new urban park. This would allow the landscape to heal and, in turn, potentially heal relations with the Algonquin people. Secondly, the plan would incorporate and honor the tradition of the falls as a meeting place and potentially as a tourist attraction, enticing visitors from around Canada and the world. Finally, as the Eastern portion of Victoria Island has already been designated for an Aboriginal Centre, this would help jump-start the project by Mr. Cardinal.

As Algonquin poet and speaker Albert Dumont points out, despite being unable to access the falls for years, they still have a powerful hold on the Algonquin mindset:

Though in a weakened state, the Ottawa river's waters [fall] into

the Kettle with a great spiritual force, still carrying within its boiling bubbles the hopes and dreams that the Anishinabe, who had lived around them for many thousands of years, had for their descendants living today and far into tomorrow. ${ }^{112}$

112 Dumont, Albert. "The Kettle of Boiling Waters: Chaudî̃"re Falls, Algonquin Territory." Turtle Moons Contemplations. http://albertdumont.com/the-kettle-of-boiling- 
The spiritual connection to the falls was not lost on the early European explorers. Champlain himself wrote about a ceremony he witnessed where an offering of tobacco was made to the river in order to secure protection and safe passage. ${ }^{113}$ It is ultimately Mr. Dumont's belief that, given the long Algonquin history of the site, any development on the site must include a place where "the Algonquins can go and once again offer tobacco and prayer for the health and well-being of the river."114

In the midst of working on this thesis it was announced that Windmill Development Group had successfully negotiated the purchase of the Domtar Lands from Domtar Inc. On December 11th 2013, they held the first public waters-chaudiere-falls-algonquin-territory/ (accessed March 21, 2014).

113 Morrison, James. "Algonquin History in the Ottawa River Watershed." in

A Background Study for Nomination of the Ottawa River Under the Canadian

Heritage Rivers System. Petawawa: Ottawa River Heritage Designation

Committee, 2005. http://www.ottawariver.org/pdf/O-ORHDC.pdf (accessed March 19, 2014) 21-22.

114 Dumont, Albert. "The Kettle..." 
consultation about the project, tentatively known as "The Isles."115 Windmill is prepared to deal with a situation that few others would dare face, namely the complex property rights of the Domtar lands. There are two stakeholders the Chaudière Corporation and Domtar, as well as Hydro Ottawa, Hydro Quebec, First Nations claims, the federal government, Ontario and Quebec provincial governments, and two municipalities. ${ }^{116}$ There are also the complexities involved with the remediation of a former industrial site. Unfortunately, it appears that a number of Mr. Padolsky's fears documented in his 1984 study have come to fruition; namely, the "demolition by neglect" of the Booth Board Mill. ${ }^{117}$ In recent conversations with Mr. Padolsky, Scott Demark and Derek Howe (are partners at Windmill Development) revealed that the building is in a major state of disrepair (figures 18.1 \& 18.2). Both Mr. Demark and Mr. 115 Windmill Development. "WINDMILL DEVELOPMENT GROUP SIGNS AGREEMENT TO PURCHASE DOMTAR GATINEAU AND OTTAWA LANDS." December 4, 2013.

116 Bassett, "Logjammed."

117 Payne, Elizabeth. "Domtar buildings need..." 


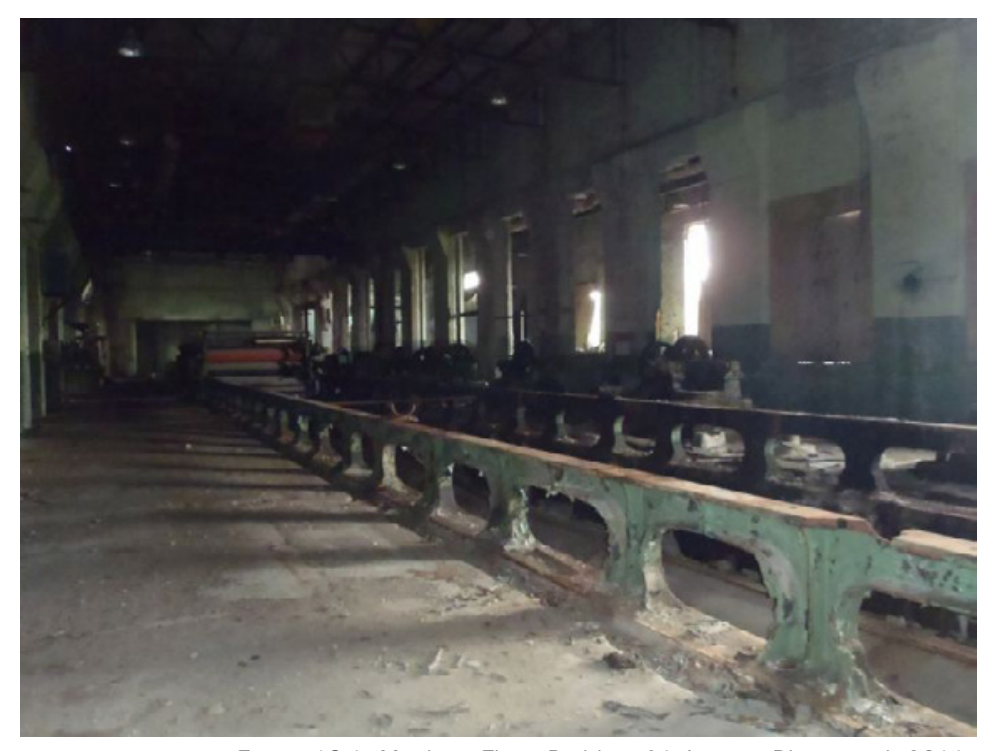

Figure 18.1: Machine Floor, Building 31, Interior Photograph 2011

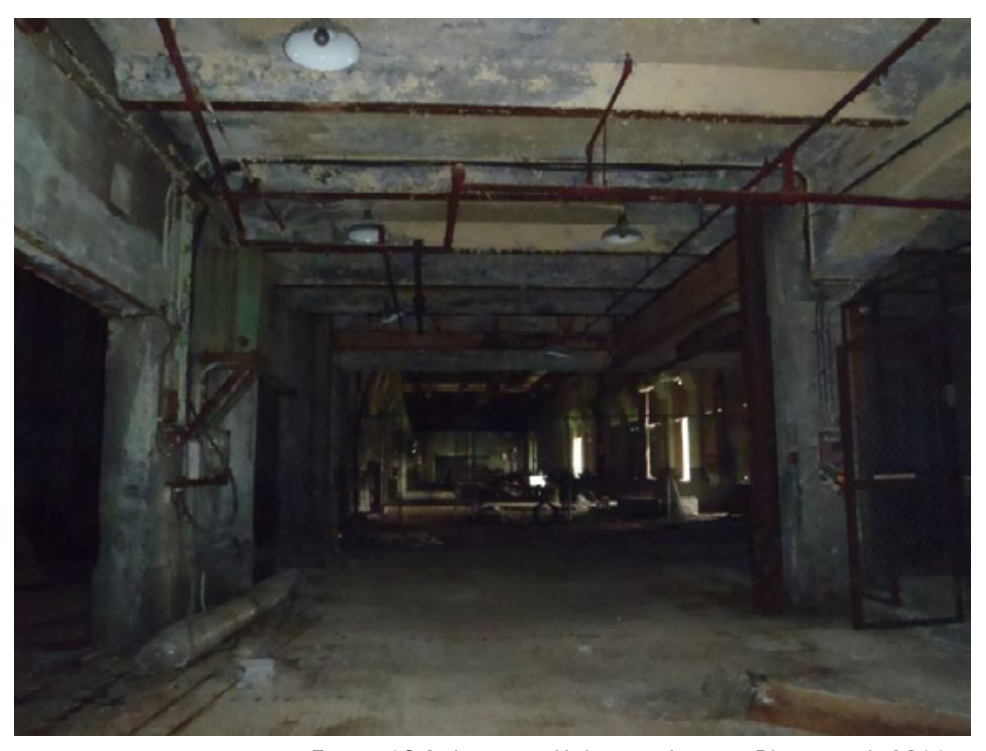

Figure 18.2: Location Unknown, Interior Photograph 2011

Howe mentioned that at least portions of the Board Mill are beyond repair, facing structural failures, and for the redevelopment to take place, large sections, if not the entire building, will need to be demolished. ${ }^{118}$ From

118 Scott Demark, November 8, 2013.

And: Derek Howe, conversation with author December 11, 2013. 
a development standpoint, the issue that was of grave concern - the sites potential contamination - is not nearly as dire as once thought. Domtar's vice-president of corporate communications Pascal Bossè estimates that "the cleanup would cost less than 5 million" on the Quebec side. ${ }^{119}$ Mr. Demark confirmed in our recent conversation that, while he could not release any specific information due to confidentiality agreements, the contamination on Chaudière Island is not as significant as once feared, especially given the site's long industrial history. ${ }^{120}$

119 Payne, Elizabeth. "Domtar lands cleanup won't be too costly, environmental assessment suggests." Ottawa Citizen, August 9, 2013. http://www.ottawacitizen.com/ technology/Domtar+lands+cleanup +costly+environmental+assessment+suggests/8770260/ story.html (accessed November 18, 2013)

120 Scott Demark, November 8, 2013. 


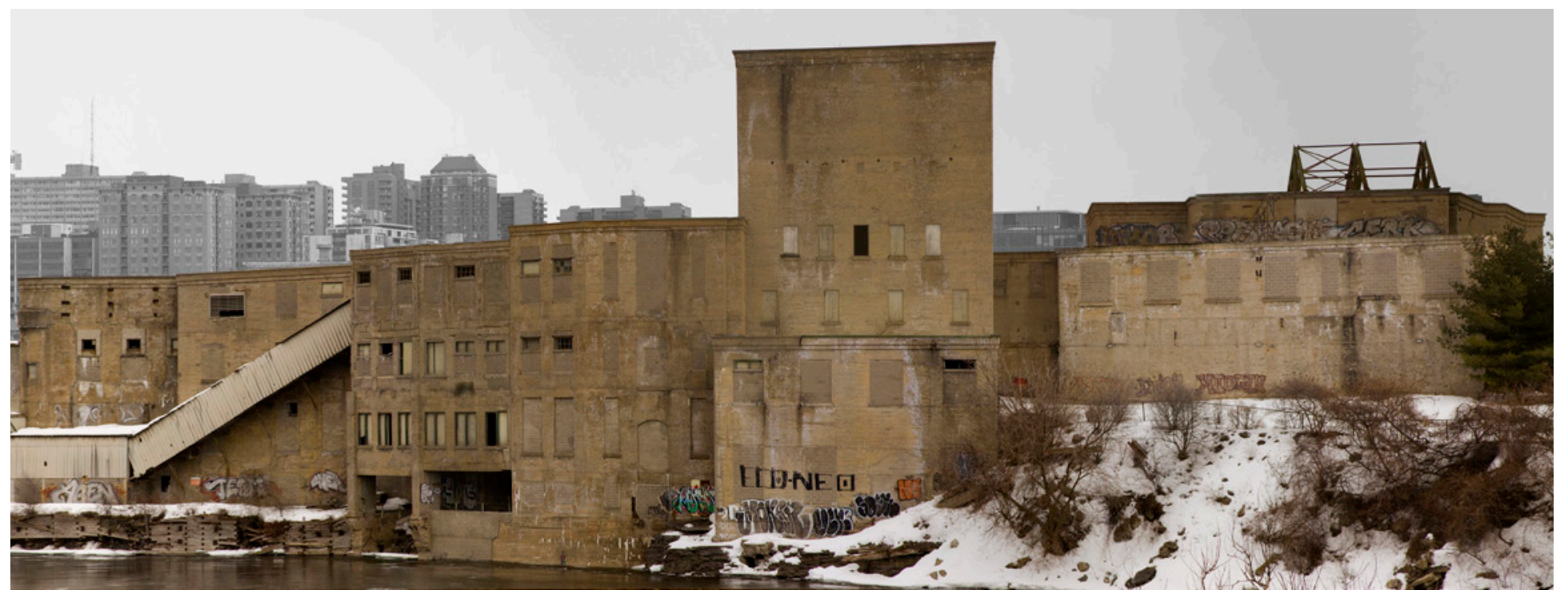

Figure 19: The Booth Board Mill from the North 2013. 


\section{[Design: Program Generation]}

Having examined the traits and characteristics of skateboarding as an urban practice, there are a number of interesting overlaps with the events surrounding Windmill's proposed development of the Domtar lands. I believe these overlaps provide tangible examples of how skateboarding can be valuable as an alternative design practice. What follows, then, is intended to be an illustrative example of designing through the "lens" of skateboarding, rather than a comprehensive design solution for Chaudière Island and the Domtar lands overall. 


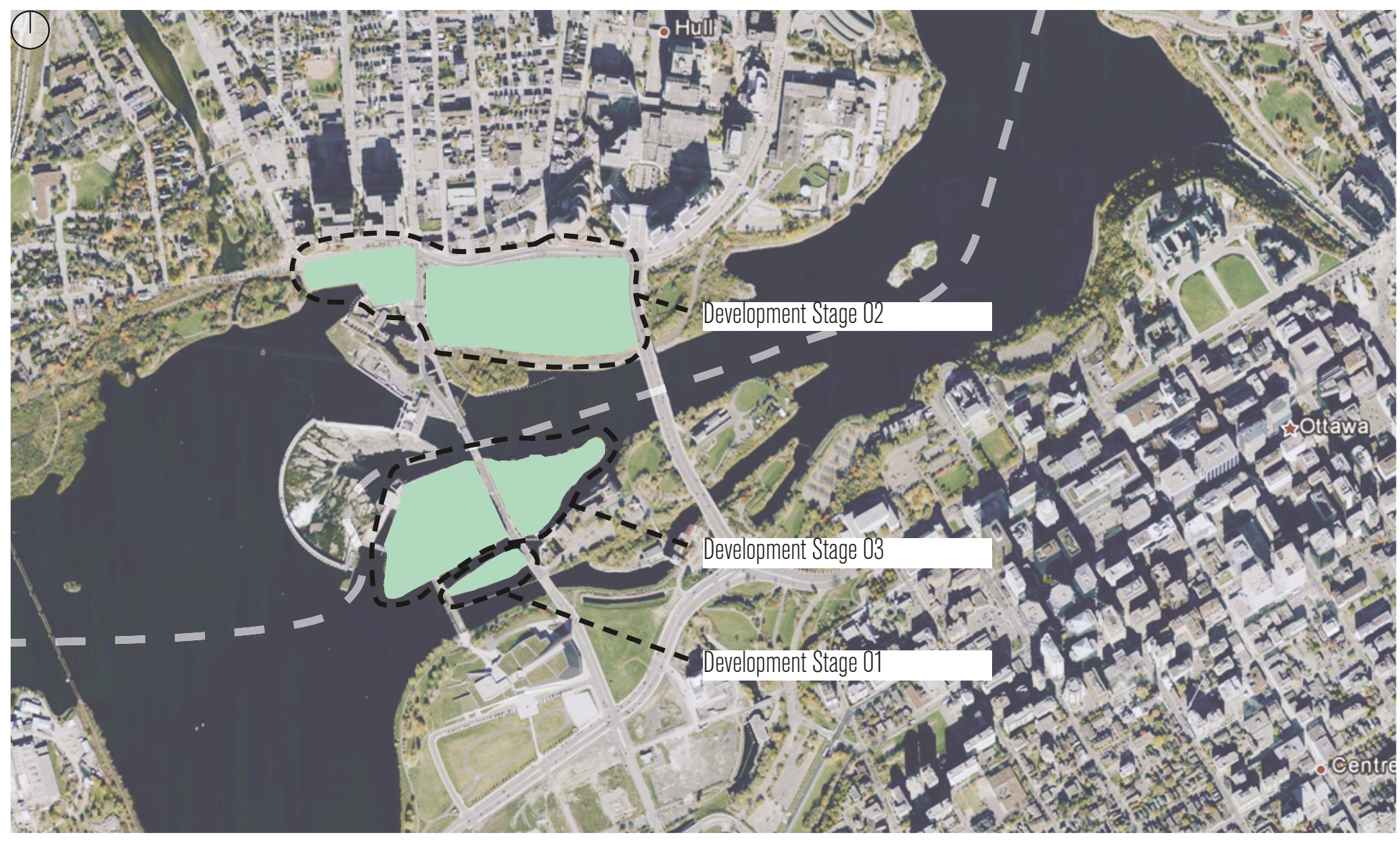

Figure 20: Windmill's proposed development sequence. 
During our conversation in November, Mr. Demark noted that Windmill's projected development scheme (figure 20) was scheduled to begin on Albert Island, breaking ground sometime in the spring of 2015. From Albert Island, the intent is to then cross over and begin the long process of developing the Quebec side before finally returning to Chaudière Island. While there are a number of practical considerations that went into planning the course of events, this ultimately means that Chaudière Island is set to remain unused for several more years. I believe that this is both unacceptable and a great disservice to who wish to access the area. Even now, there are numerous footpaths onto and across the snow leading up to the Booth Board Mill (figure 21), clearly illustrating the publics interest in the area - all despite the sizable "No Trespassing" signs littering the property. 
In order to correct what I see as a missed opportunity by Windmill Development, I propose appropriating a portion of Chaudière Island and creating a temporary occupation of the space. The ultimate intent of this is to immediately bring use back to the site in advance of Windmill's

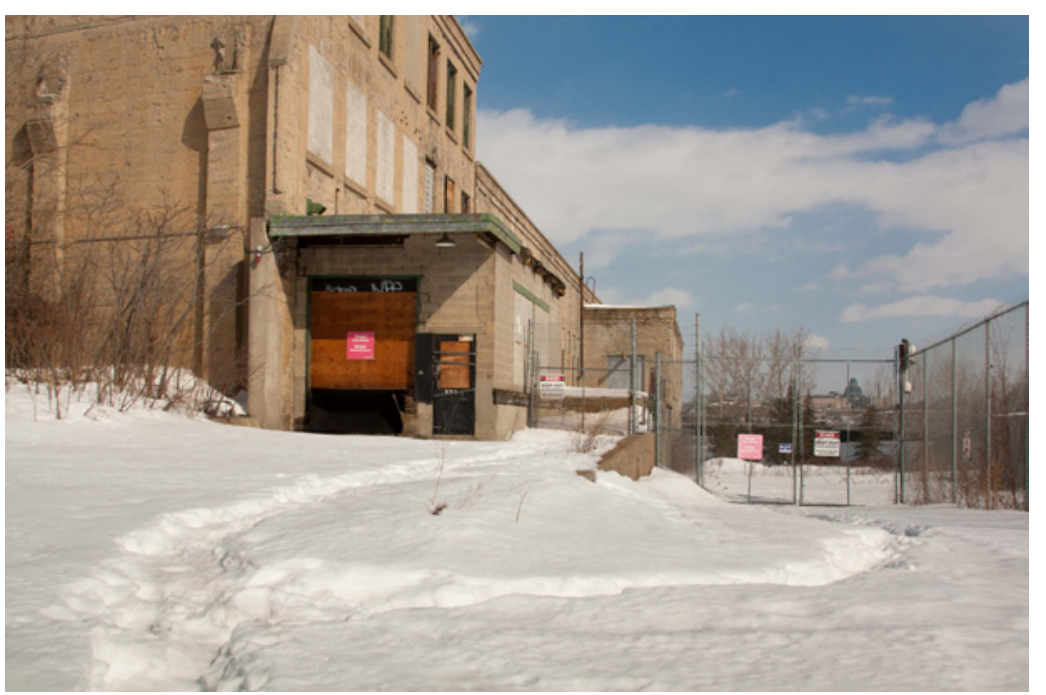

Figure 21: People are constantly trying to access the Board Mill. schedule. As it was laid out for me, that schedule would add several more years of inactivity to a portion of the city that has been underutilized for far too long already. By approaching the design from the perspective of a skateboarder, it is possible to create a solution that jump-starts the redevelopment project. It also utilizes portable or temporary architectural 


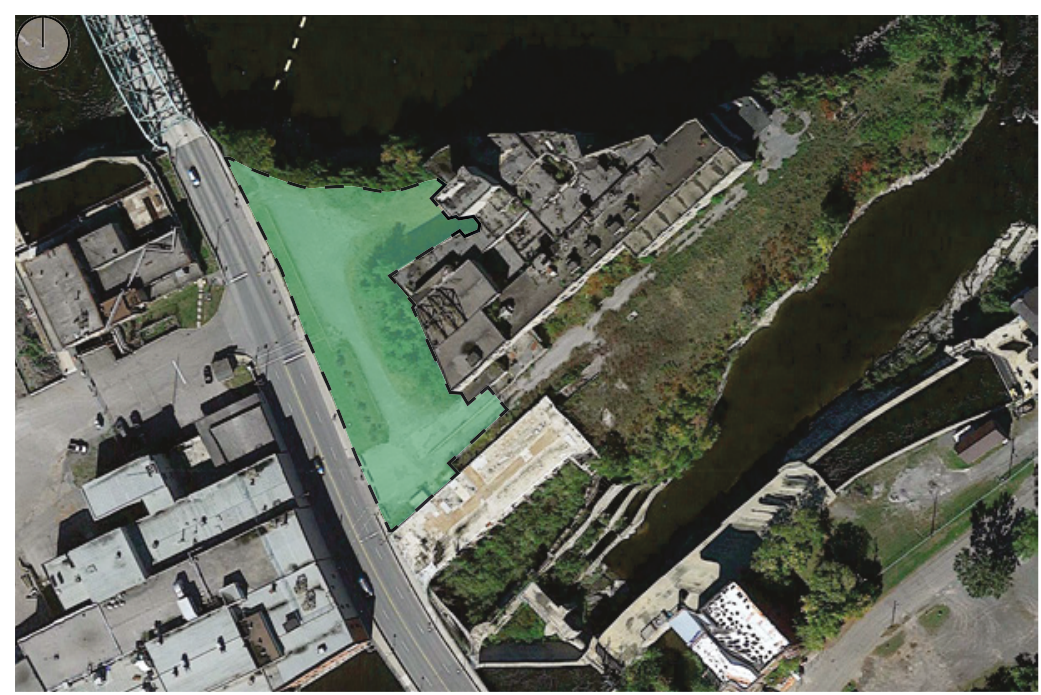

Figure 22: The site for appropriation. interventions that can be easily

disassembled, relocated, or

re-purposed when full-scale

development commences.

While considerable time and

attention was spent studying the

Booth Board Mill as the site the aforementioned appropriation, ultimately it was decided that

this was not the best course of action, given the buildings' complexities.

Rather, it was decided that the portion of land located between Booth

Street and the Board Mill (figure 22) was the best location for the project.

This site is of particular importance for a number of reasons. First and

foremost, as with any appropriation attempt, access is of vital importance. 


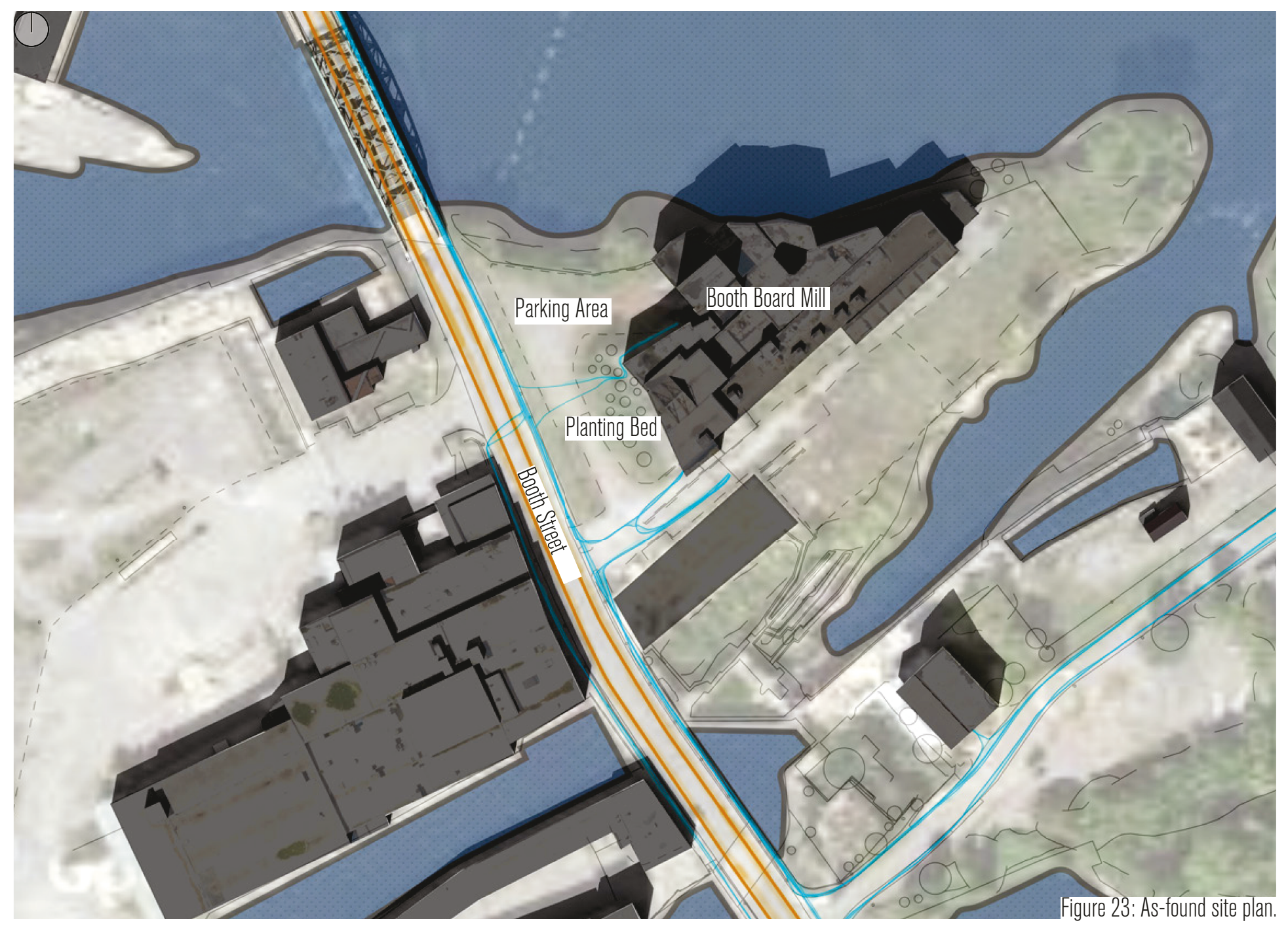



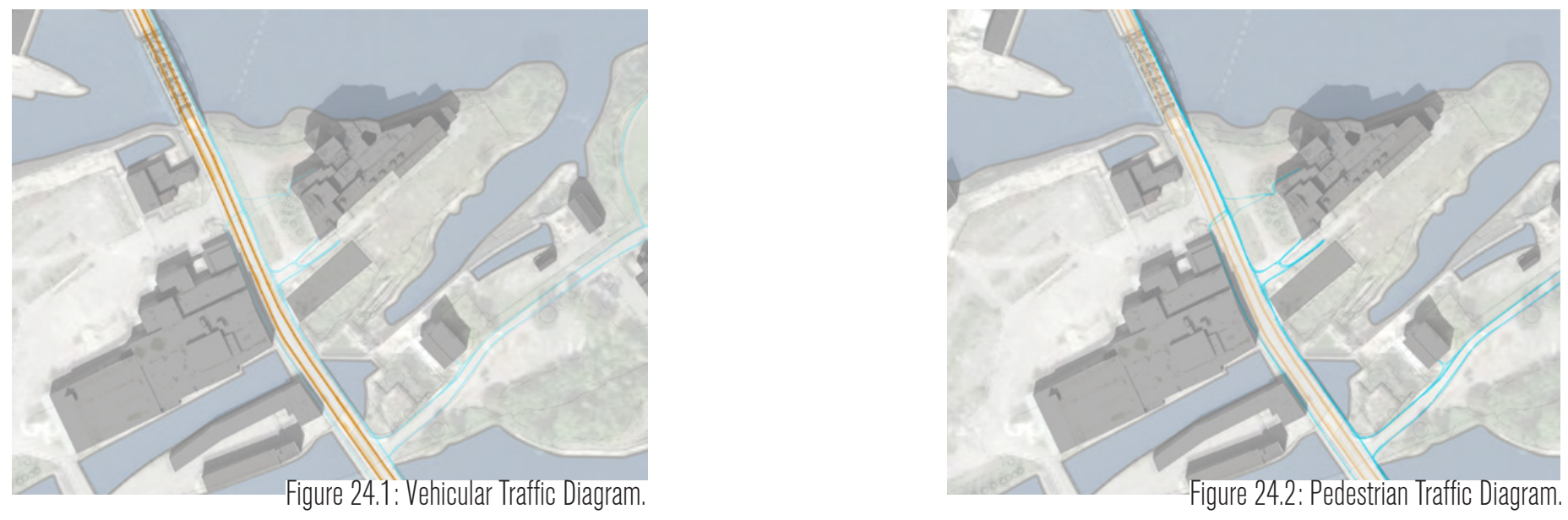

This portion of land is entirely and immediately accessible: framed by the river to the north; the building facade to the east; an existing fence to the south; and Booth street to the west. Secondly, given that this area formerly housed a loading dock and parking area, there is ample room to move and configure any component pieces that may be required. Also, the roadway and parking areas were designed to accommodate loaded lumber trucks, so there is little need to worry about their bearing capacity. Finally, the site is centrally located within the Domtar lands, immediately adjacent to Booth Street, and in close proximity to a number of important attractions in the Ottawa-Gatineau region. All of this has an influence on site's programming. 


\section{[Design]}

When navigating the urban fabric, skateboarders have a particular set of considerations that I can now apply within the context of the Chaudière Island site to guide the design. First and foremost, skateboarders place use over any notion of ownership or private property. In this particular case, we are placing use over the ownership rights of Windmill Development. While the legality, or rather illegality, of these actions are beyond question, the case studies laid out previously show that this does not always or immediately result in an impasse. The key, then, is the skateboarder's ability to provide some sort of value or benefit that outweighs their illegal appropriation of the space. In all three case studies, the skateboarders' presence forced out the even more reprehensible user groups - namely the 


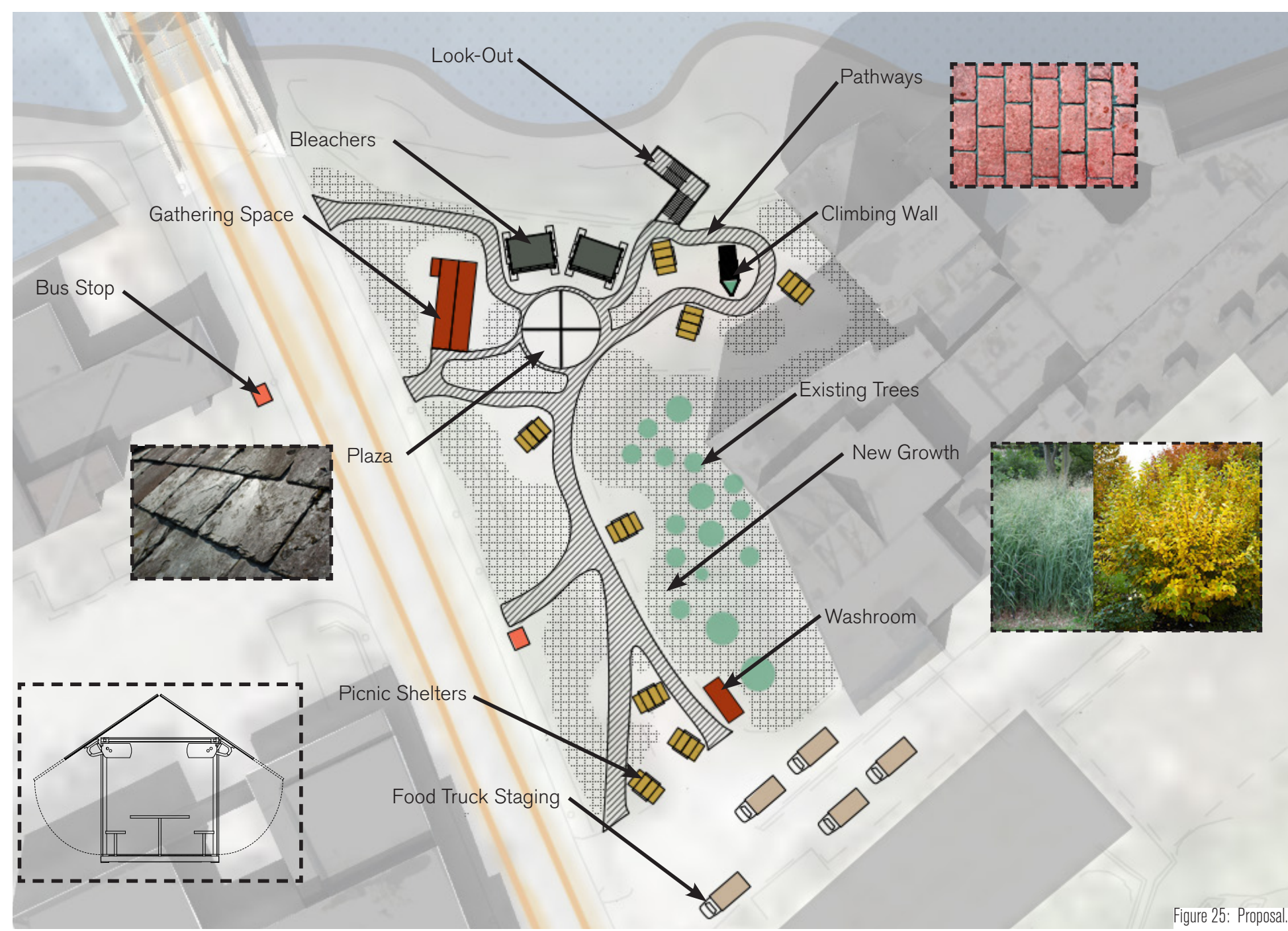




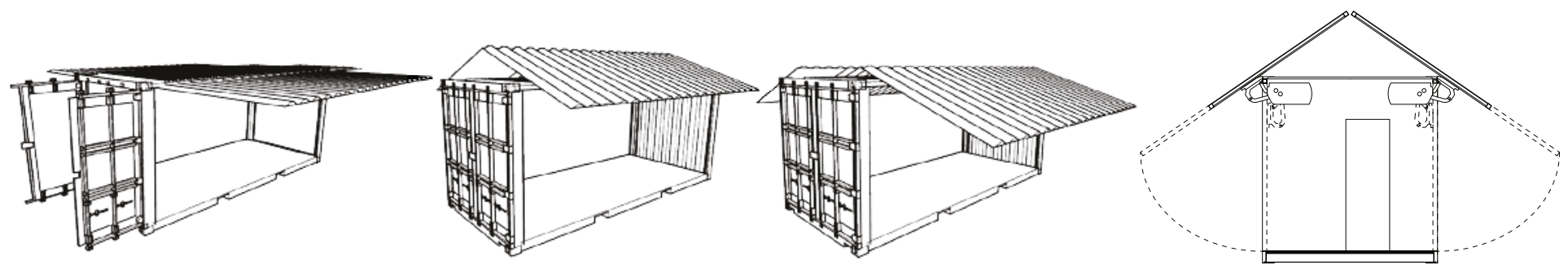

Figure 26: Shipping container studies.

Figure 27: Hinge study

homeless, drug addicts and prostitutes. As such, they were tolerated, at least for the time being. In the case of Chaudière Island, unlike in the skateboarding case studies, it is not the goal to force out any pre-existing user groups. On the contrary, the goal is to actually bring more activity to the site, and as such, there must be some other tactic used to placate the property owners and allow the appropriation to occur.

In this particular instance, as Windmill begins construction, they will be faced with a very pertinent problem: The Domtar lands and Albert Island in particular (Development stage 01) are in a mini food desert. Working from first-hand experience, there are few things of greater concern 
Downward Force:

$17,329 \mathrm{ft}$. Ibs.

28.1 cu.ft.

Salvaged Concrete

@ 150 lbs/ cu.ft.

Downward Force:

$54,671 \mathrm{ft}$. lbs.

$=$

Total Downward Force:

$72,000 \mathrm{ft.lbs}$

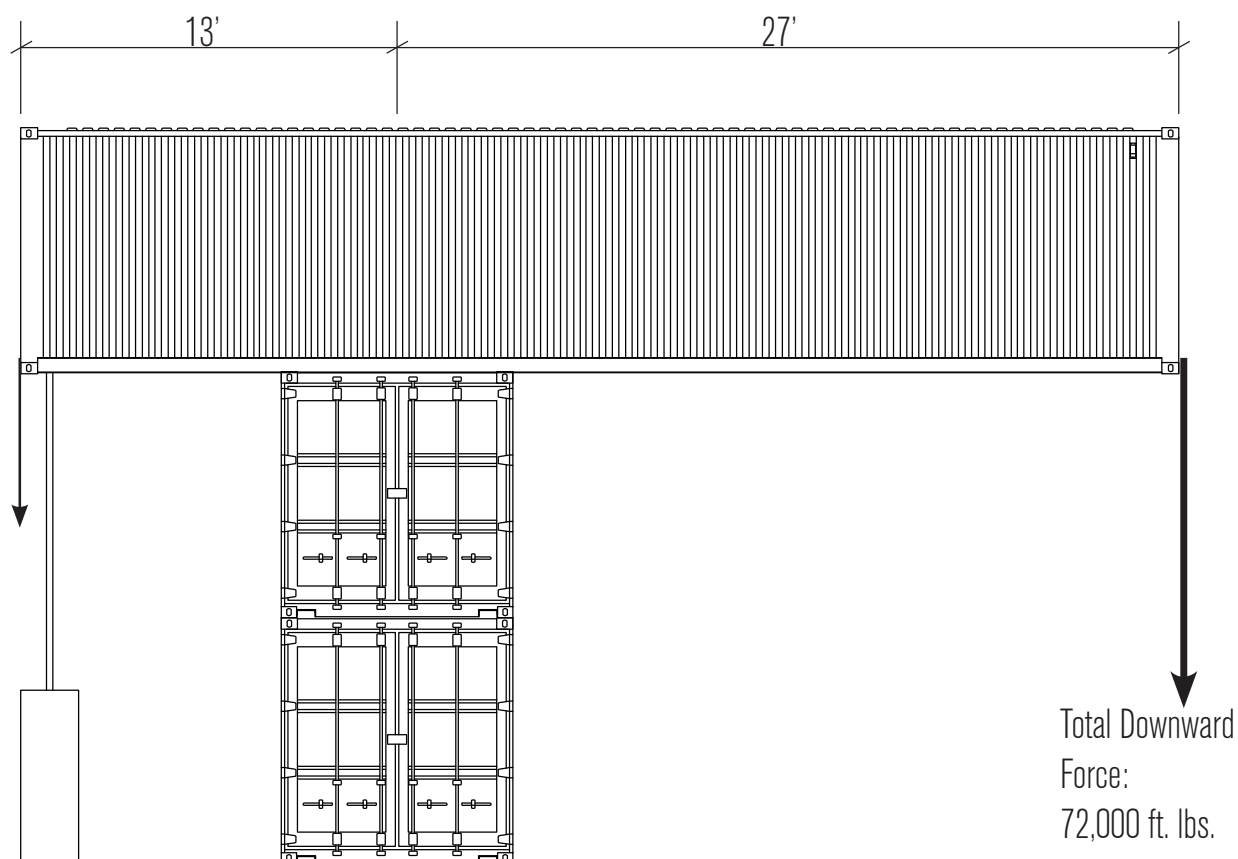

Figure 28: Cantilever study.

to a construction crew than having access to cigarettes, coffee and slushy

drinks in the summer time. Thus, by accommodating and incorporating a space

on the site for either food or concession trucks, it will provide a tangible

benefit for Windmill. This will decrease the amount of time spent on break

by significantly reducing the distance workers have to travel for these

"necessities," in turn allowing them to get more productive working time 

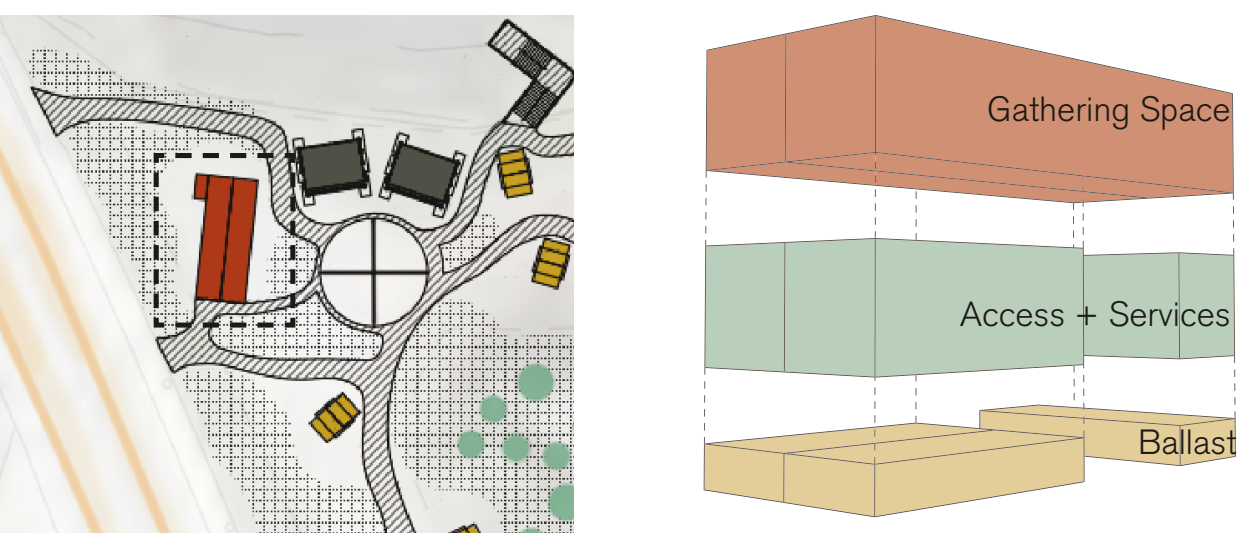

Figure 29: Gathering Space and Concept Diagram

per day. It will also decrease the amount of vehicular traffic through the construction zone, which will improve the site's safety. Also, by providing space on Windmill property for these trucks to operate, Windmill would be able to issue some form of licensing fee the owner/operators pay in order to have access to the masses of hungry construction workers.

A second major consideration as skateboarders navigate the urban fabric is the presence and exploitation of cycles, patterns and flows. For the skateboarder navigating in the city center, the flow of traffic and movement of pedestrians must be accounted for and negotiated to avoid getting run over or running someone over. In the case of street skating, the work cycles 


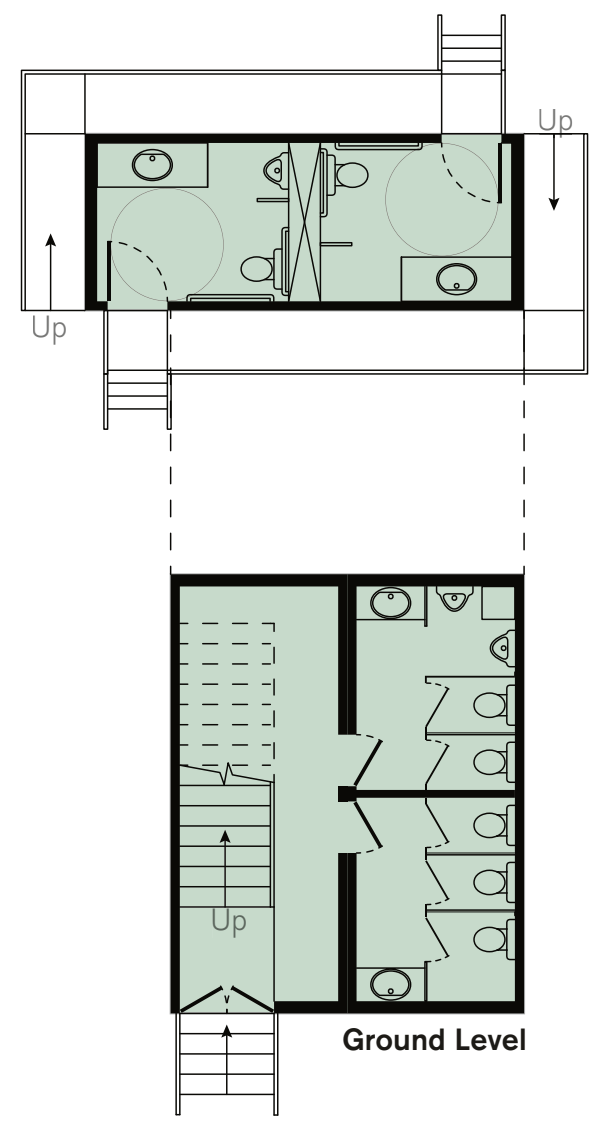

Figure 30: Gathering Space Layout

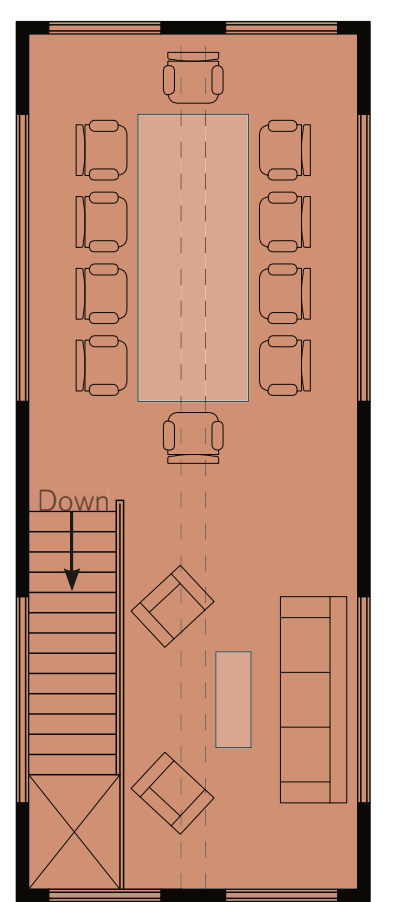

Upper Level

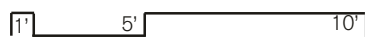

The incorporation of food trucks into the appropriation also takes into consideration the cyclical nature of the work being completed by Windmill. 


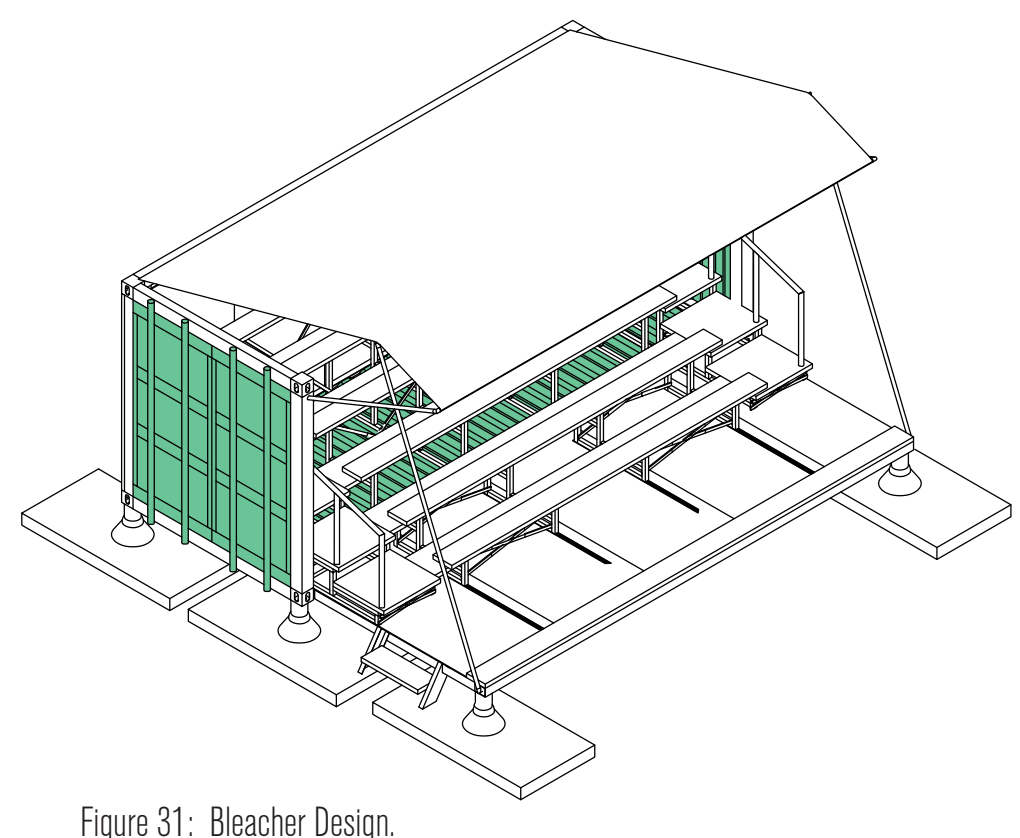

in which the site is unoccupied. By incorporating elements such as covered seating areas (figures 26 and 31), not only will the workers be happier and more comfortable, it provides something to draw people in beyond working hours. Most immediately, these structures can serve as some form of shelter for pedestrians - either those crossing the Ottawa River, or those drawn up from the Ottawa River Pathway which crosses Booth street just south of the site. This increases active hours to include morning and evening commuters. 


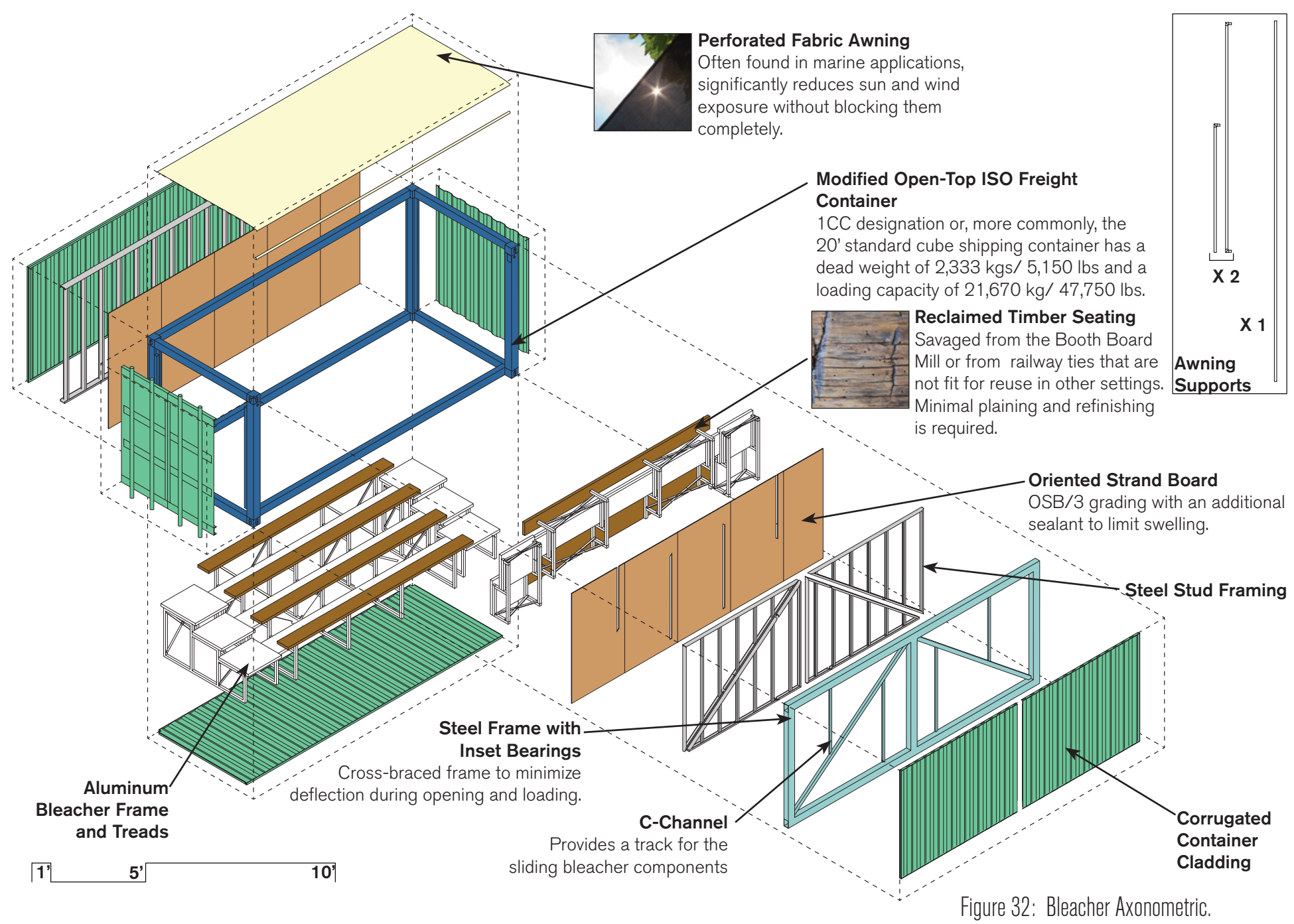

Figure 32: Bleacher Axonometric 

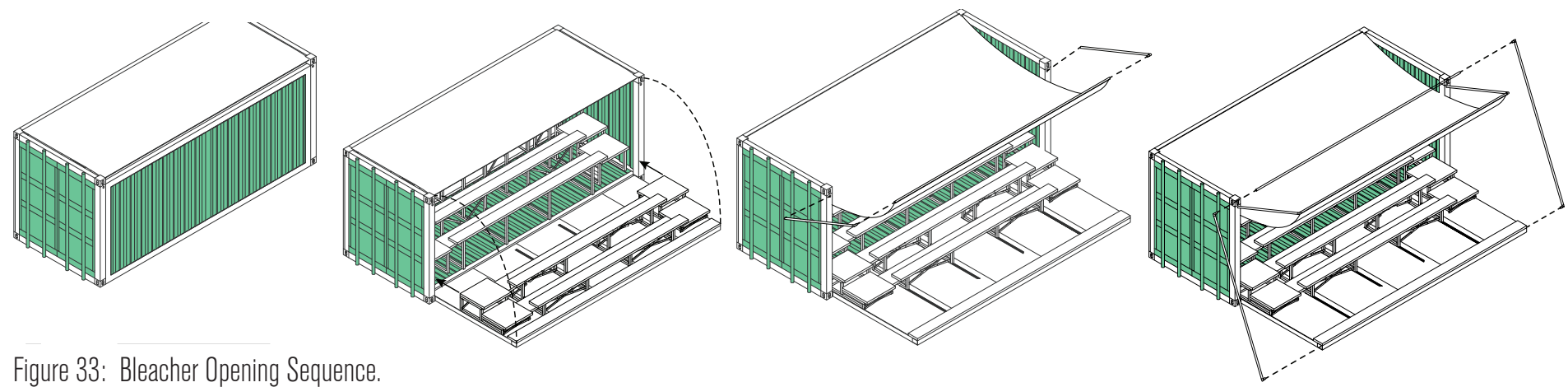

Figure 33: Bleacher Opening Sequence.

Unique additions such as a mobile climbing wall (figures 34 and 35) work to attract recreational users in the evening during the week and all day on the weekends. Then with the appropriate and well thought-out lighting installations can push these active hours even further.

Approaching the appropriation from a less pragmatic angle, there is also a need to address the most overlooked user group in Chaudière Island's history: the First Nations. As it was mentioned previously, the Chaudière Falls are, to this day, of critical concern for the First Nations. As such, no development or even appropriation can rightly proceed without addressing their concerns. While not being of First Nations decent myself, and having 
no real design training from a First Nations perspective, it is naive to think that I can provide a comprehensive design for the First Nations people. What I attempt to do, however, is look at Mr. Commanda's four-fold vision for the area and incorporate key components of his design into my work. Within the design I have included both a gathering place which could hold small scale assemblies year round figures 29 and 30), as well as larger out-door gatherings when

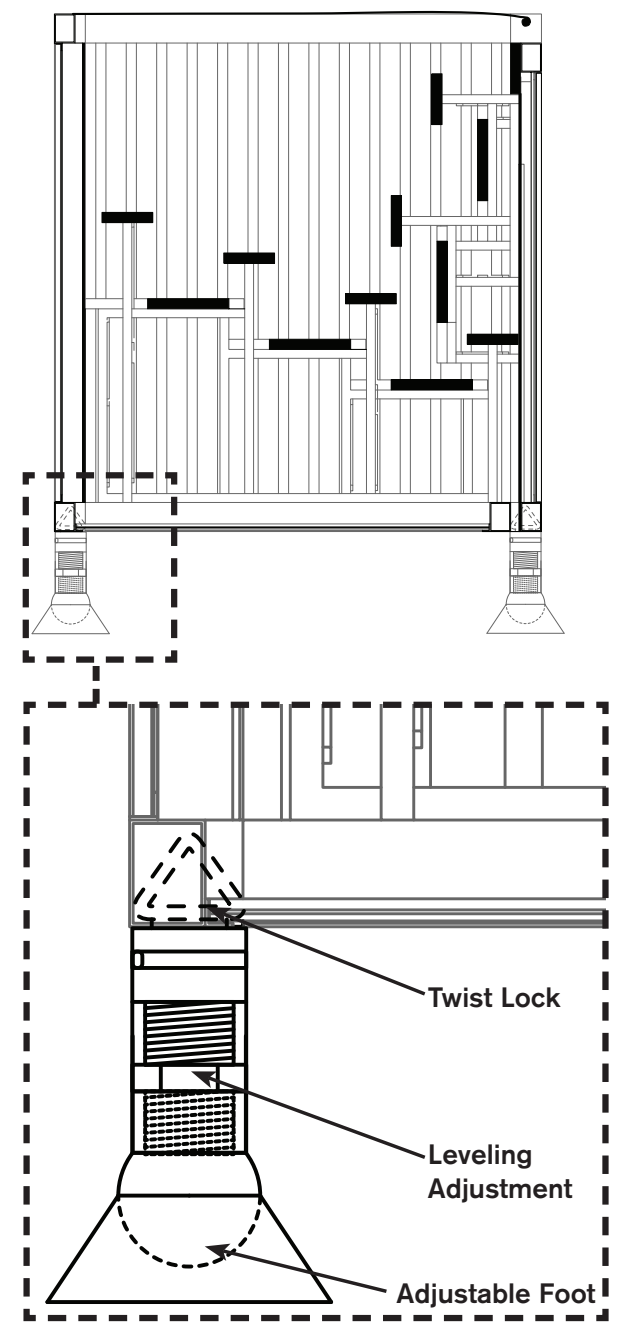

Figure 34: Bleacher Section and Foot Detail. 
the weather permits (figures 31 and 32). There is also the addition of a look-out on the north side of the site which once again allows views to the Falls and access to the river which was outlined as a major concern for the First Nations People, and more specifically, the concerns of Mr. Dumont. Overall, there seems a poetic justice at work when it takes an act of appropriation to return, at least in part, this land to whom it was taken from so many years ago

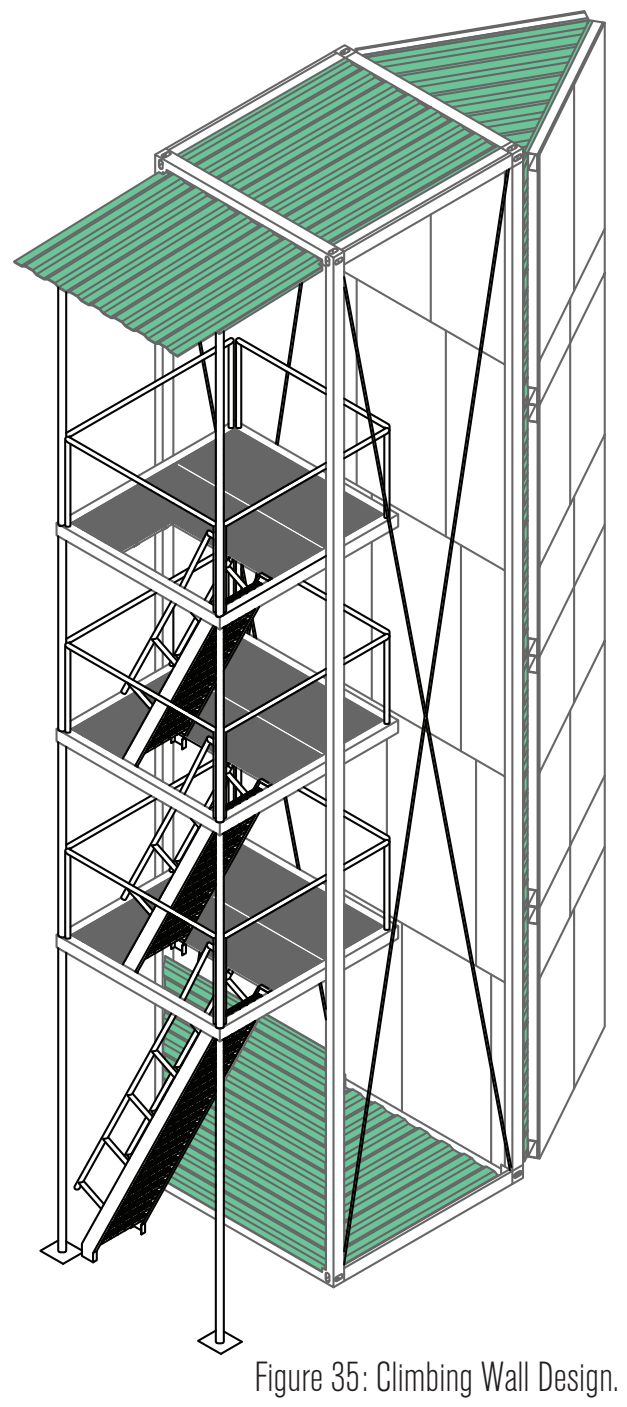



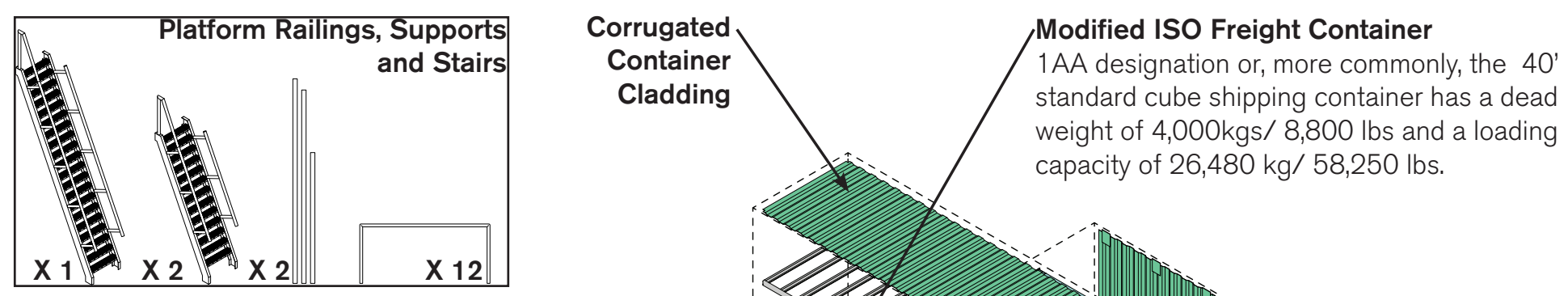

Oriented Strand Board with Rigid Urethane Climbing Holds OSB/3 grading with an additional sealant to limit swelling.

Steel Stud Framing

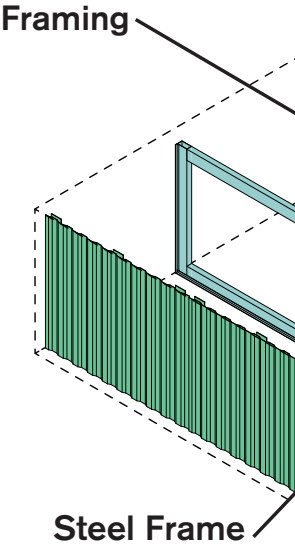

with $270^{\circ}$ Hinges

Divided into 4 sections to reduce weight, each panel locks into the adjoining panel when open.

of $26,480 \mathrm{~kg} / 58,250 \mathrm{lbs}$. 


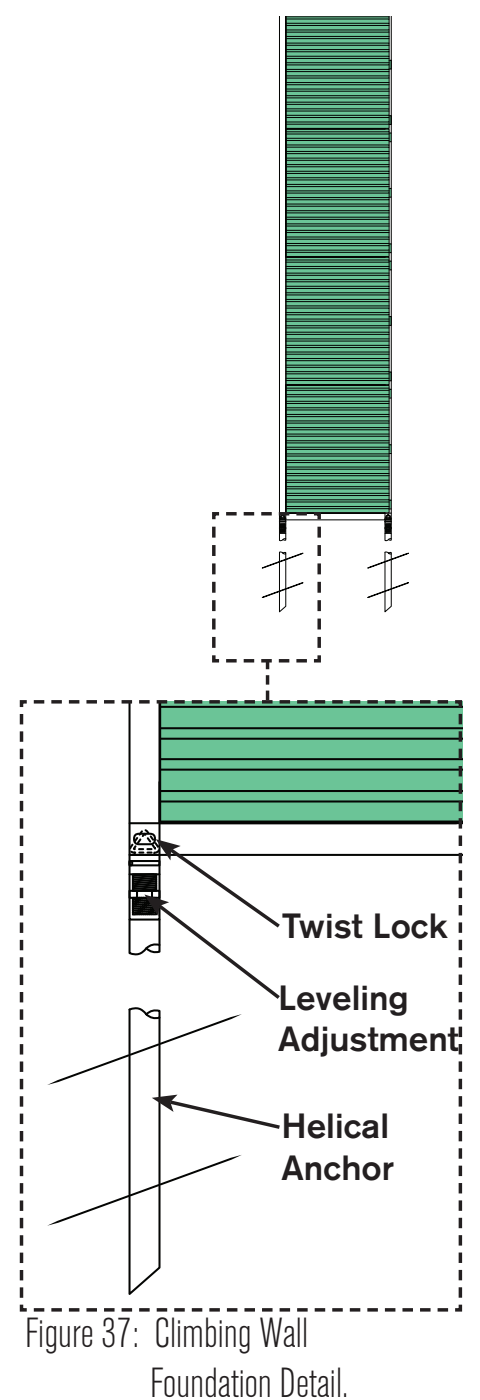

The final aspect of a skateboarder's navigation of the urban fabric is the physical make-up or materiality of the city. This is important because as skateboarders travel across different surfaces, they are keenly aware of changes in materiality and texture as it is physically registered through the skateboard and up into their body. They are also aware of additional cues provided by the auditory aspect of the wheels passing over a surface. As surfaces change, the level of effort required to move across them changes as well. Asphalt, for example, changes quite rapidly year to year from a skateboarder's perspective because of the freeze/thaw 

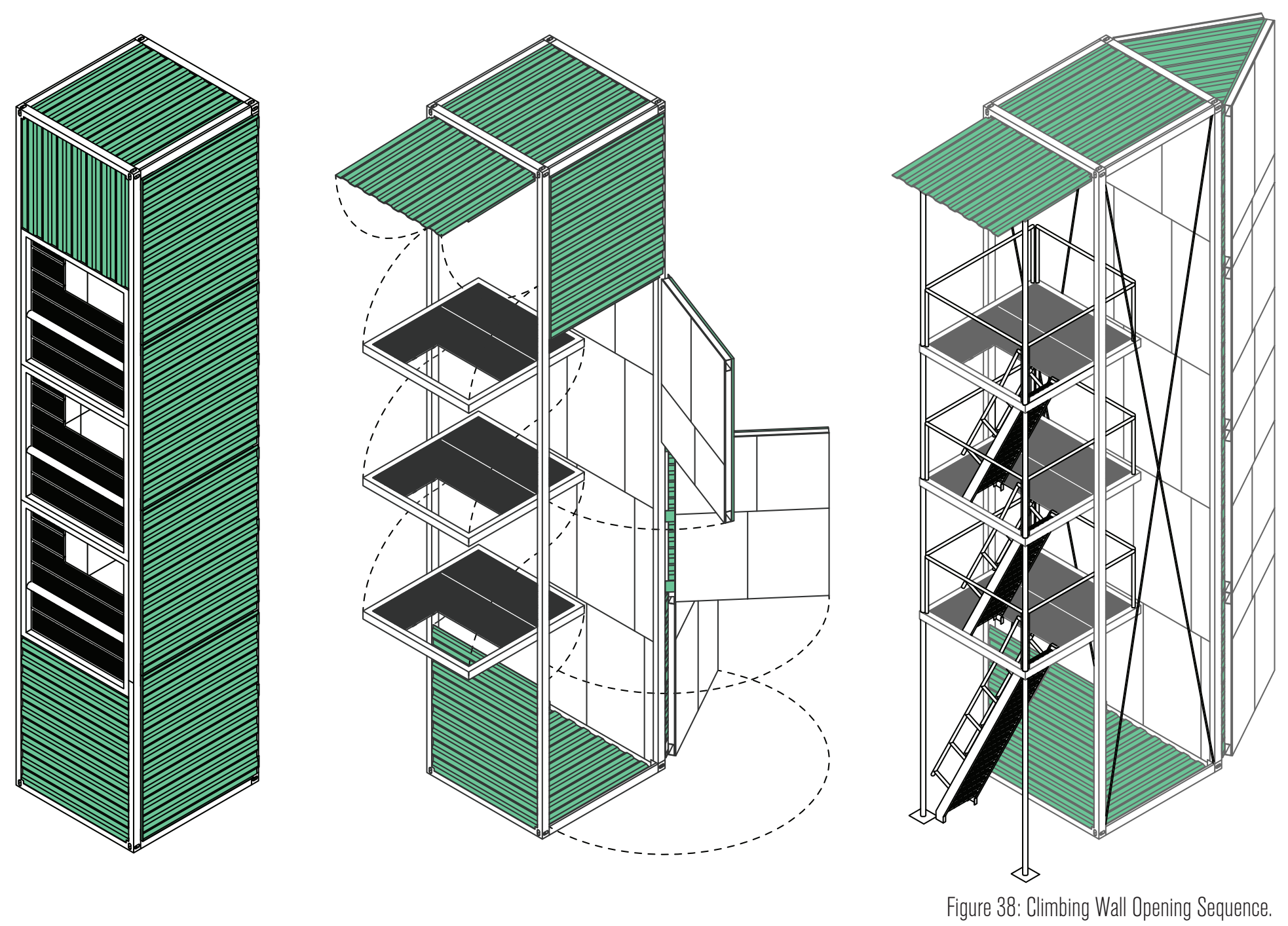
cycle. Fresh asphalt is smooth, quiet, and full of traction; a joy to ride. Even after a single winter, however, it becomes harsher, louder, and rougher despite no significant visual changes. Ultimately, this results in a more complete and fully engaged experience of architecture, which is what we as architects aspire to create and foster.

The materiality of the appropriation can then be seen as an important way to engage the different user groups. Given the proximity to the Booth Board Mill and its imminent destruction, there appears a perfect opportunity to try and re-purpose some of the building materials. Concrete slabs, concrete masonry units, bricks, heavy timber, and dimensional lumber all offer unique opportunities to play with materiality while keeping waste out of the landfill and acknowledging the industrial history of the site. There is also a case for the use of materials such as railway ties, pallets, and shipping containers because of their ubiquity, versatility and general affordability. 


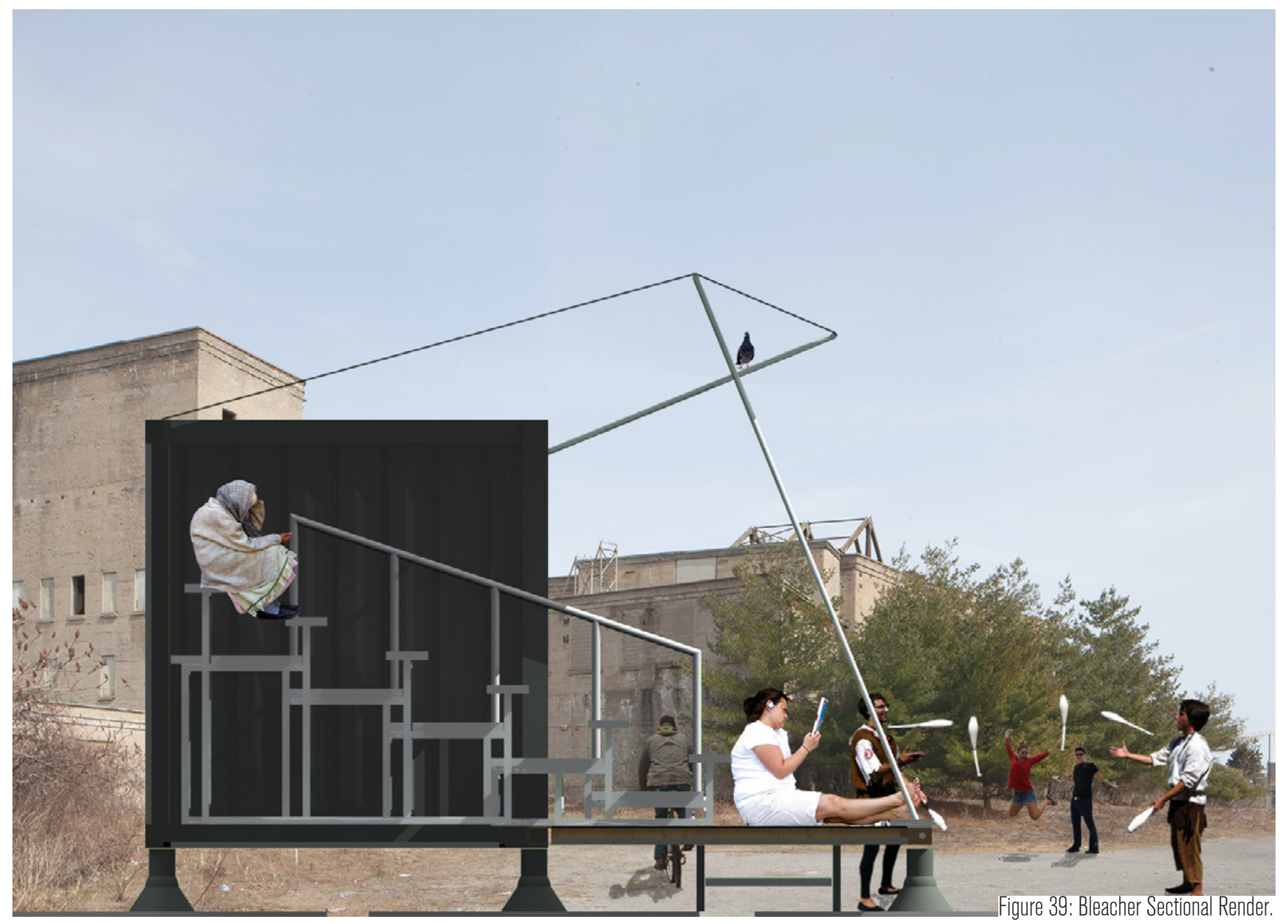




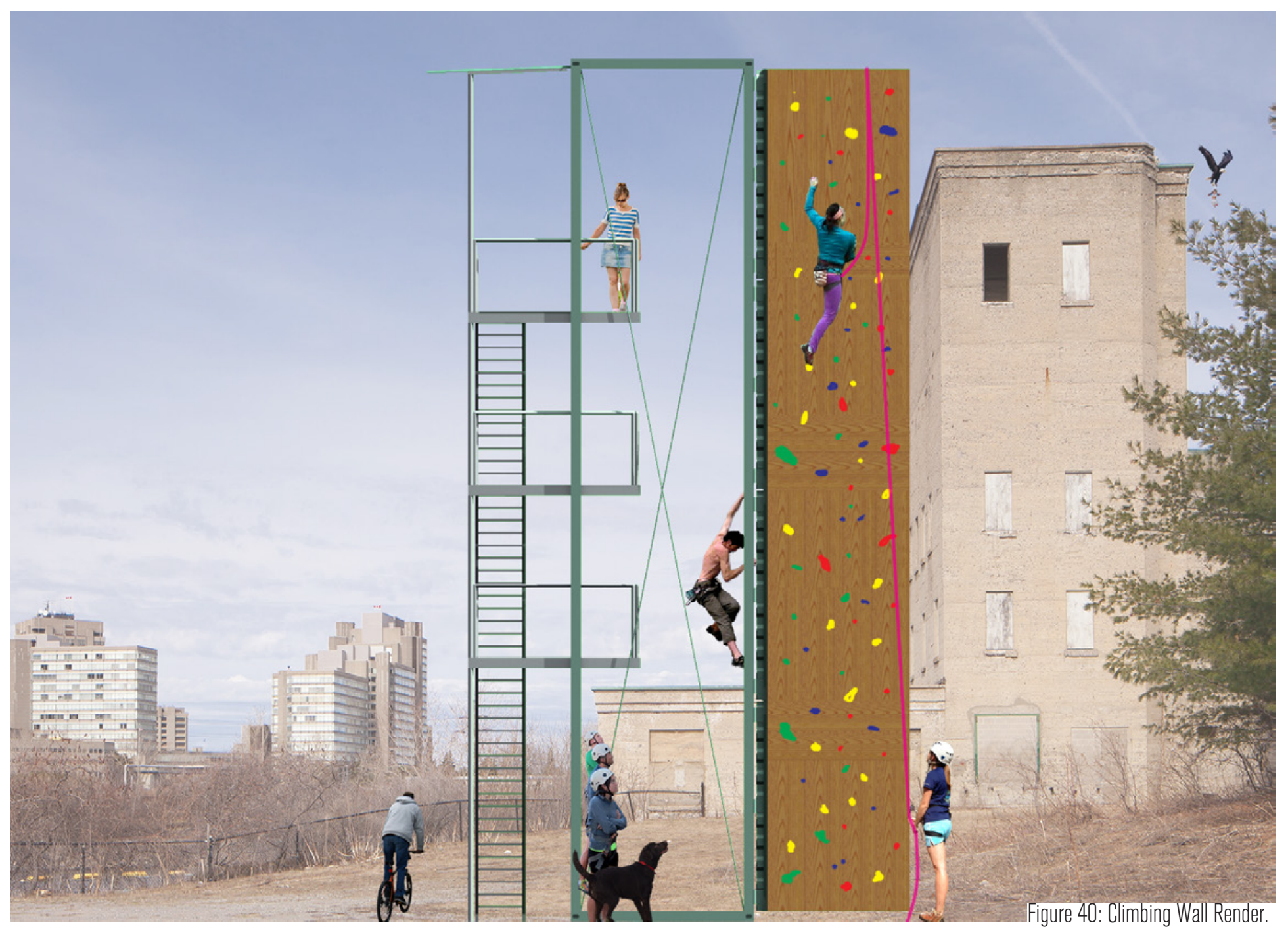




\section{[Conclusion]}

Skateboarding, as a uniquely urban practice, clearly demonstrates a number of significant connections with architecture. Physical engagement, material, scale, and consequence all work in unison to shape how skateboarders see the world. With both architects and skateboarders approaching the city from unique, but slightly overlapping perspectives, there is a wonderful potential for criticism and collaboration.

With this project in particular, there were a number of difficulties that needed to be addressed; In the case of Chaudière Island, there was a considerable struggle mediating between the site's long and complicated history and the proposed appropriation. When I originally set to work on this thesis, the fate of Chaudière Island was very much up in the air, but as my work progressed and Windmill Development's unveiling occurred, the site became a hot-bed of speculation. As a result, the project that emerged was, 
understandably, forced to compromise between a hotly contested location, and a rigorous examination of the architectural potential of skateboarding. With my own interest being the latter, it becomes apparent that my approach would be better suited to a different site.

Ultimately, it is my hope that this thesis can serve as the theoretical framework for more thorough and in-depth, design-based explorations in the future. My own work is bound to continue along this trajectory for the foreseeable future. Of particular interest is how a broader architectural strategy could be developed which, to borrow a phrase from stewart Brand, could utilize a skateboarder-influenced "low-road" building solution. The key to this seems to precipitate in skateboarder's mobility, embrace of temporality, and the celebration of use-value over ownership. While my 
current proposal does take these characteristics into account, it would be a valuable exploration to see how much further they could be taken on a less controversial site.

Architects have long been known for their desire to experiment with different modes and methods of living, knowing that there is no singularly perfect solution. The following question was set out for me during my defense: "What is the architecture of skateboarding? Or rather, what is the perfect architecture for skateboarding?" and I believe the answer relates the practice of architecture with that of skateboarding quite succinctly. Truthfully, most skateboarders would love a little patch of land with a negligent landlord, away from prying eyes, and a few bags of cement so they can figure "perfect" out for themselves. 


\section{[List of Figures]}

Figure 1: Guy Debord, The naked city : illustration de hypothèse des plagues tournantes en psychogéographique / G.-E. Debord, 1957. Permild \& Rosengren. <http://brbl-dl.library.yale.edu/vufind/Record/3590760> accessed March 30, 2014.

Figure 2: Skateboarder performing a kickflip, 2011, image copyright author.

Figure 3: Skateboard component diagram, 2013 image copyright author.

Figure 4: Skateboarder riding in a pool, 2011, image copyright author.

Figure 5: Skateboarder in a pool diagram, 2013, image copyright author.

Figure 6: Skateboard underside, 2013, image copyright author.

Figure 7: Skateboarder falling, 2011, image copyright author.

Figure 8: Skaters eye diagram \#1, 2013, image copyright author.

Figure 9: Skateboard injury, 2011, image copyright author.

Figure 10.1 and 10.2: Skateistan, title unknown, date unknown. <http://www.skateistan.org/photos> accessed March 30, 2014

Figure 11.1: Smallbones, LOVE Park Philly, 2010. <http://commons.wikimedia.org/wiki/File:LOVE_Park_Philly.JPG> accessed March 30, 2014

Figure 11.2: Michael Blabac, Kalis Verdict Model Ad, 2002. <http://skately.com/img/library/print/large/dc-shoes-kalis-verdictmodel-2002.jpg > accessed March 30, 2014

Figure 12.1: Cacophony, Burnside Skate Park, 2006. <http://commons.wikimedia.org/wiki/File:BurnsideSkatePark.jpg> accessed March 30, 2014

Figure 12.2: Kaai Benson, Alex_burnside2, 2010. <http://grind.tactics.com/wp-content/uploads/2010/04/alex_burnside2.jpg> accessed March 30, 2014

Figure 13.1: Photographer unknown, IMG 6297, 2012. 
<http://4.bp.blogspot.com/-nZ0wQwBL9-k/

UICS4GdCkEIAAAAAAAAACU/9SK6SRnhHHY/s1600/IMG 6297.JPG>

accessed March 31, 2014.

Figure 13.2: Photographer unknown, title unknown, 2011,

<http://2.bp.blogspot.com/-fhwau2AOIF8/TnUj BD2MeI/

AAAAAAAAAOI / 6 rHOFYN68mM/s1600/Screen2Bshot $\frac{\overline{0}}{2} 2 \mathrm{~B} 2011-09-$

15\%2Bat\%2B1.35.08\%2BPM.png> accessed March 30,2014

Figure 14: Skater's eye diagram \#2, 2013, image copyright author.

Figure 15: Domtar land diagram overlay, 2013, image copyright author.

Ottawa-Gatineau [satillite image]. 2013, Scale undetermined; generated by author; using "Google Earth" 45²5'15"N 7541'24"W. accessed April 03, 2013.

Figure 16: Erikkson Padolsky Architects, title unknown, 1984. Image courtesy Barry Padolsky

Figure 17.1 and 17.2: Ottawa-Gatineau [satillite image]. 2013, Scale undetermined; generated by author; using "Google Earth" 45\%25'15"N $75^{\circ} 41^{\prime} 24 " W$. accessed April 03, 2013.

Figure 17.3: City of Ottawa. 366031_2005 [map]. 1:2,000. Ottawa ON: 2005

Figure 17.4: Building progression, image copyright author

Figure 18.1: Dustonmybrain. mill 165. 2011.

<http://www.ontarioabandonedplaces.com/upload/showpic.asp?id=34367> accessed April 03, 2013

Figure 18.2: Dustonmybrain. mill 145. 2011.

<http://www.ontarioabandonedplaces.com/upload/showpic.asp?id=34365> accessed April 03, 2013

Figure 19: Board Mill view from North, image copyright author.

Figure 20: Domtar development overlay, 2013, image copyright author.

ottawa-Gatineau [satillite image]. 2013, Scale undetermined; 
generated by author; using "Google Earth" 4525'15"N 7541'24"W. accessed April 03, 2013.

Figure 21: Footpaths, 2014, image copyright author

Figure 22: Existing site overlay, 2014, image copyright author.

ottawa-Gatineau [satillite image]. 2013, Scale undetermined;

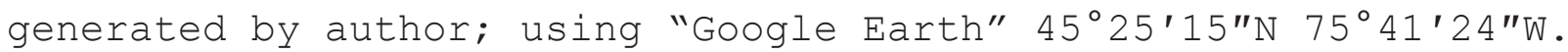
accessed April 03, 2013.

Figure 23: As-found site plan, 2014, image copyright author

Figure 24.1: Vehicular Traffic Diagram, 2014, image copyright author

Figure 24.2: Pedestrian Traffic Diagram, 2014, image copyright author

Figure 25: Design Proposal, 2014, image copyright author

Figure 26: Container study, 2014, image copyright author

Figure 27: Hinge study, 2014, image copyright author

Figure 28: Cantilever study, 2014, image copyright author

Figure 29: Gathering Space and Concept Diagram, 2014, image copyright author

Figure 30: Gathering Space Layout, 2014, image copyright author

Figure 31: Bleacher Design, 2014, image copyright author

Figure 32: Bleacher Axonometric, 2014, image copyright author

Figure 33: Bleacher Opening Sequence, 2014, image copyright author

Figure 34: Bleacher Section and Foot Detail, 2014, image copyright author

Figure 35: Climbing Wall Design, 2014, image copyright author

Figure 36: Climbing Wall Axonometric, 2014, image copyright author

Figure 37: Climbingwall Foundation Detail, 2014, image copyright author

Figure 38: Climbing Wall Opening Sequence, 2014, image copyright author

Figure 39: Bleacher Sectional Render, 2014, image copyright author

Figure 40: Climbing Wall Render, 2014, image copyright author 
"Asinabka." Asinabka. http://www.asinabka.com/index.htm (accessed March 21, 2014 ).

"Attractions \& Recreation - Skateparks." City of Edmonton. http://www. edmonton.ca/attractions_recreation/sport_recreation/skateparks.aspx (accessed November 28, 2013).

Bassett, Shannon. "Logjammed." Canadian Architect, January 1, 2007. http:// wWw. canadianarchitect.com/news/logjammed/1000209839/(accessed November 17, 2013).

Benidickson, Jamie. "Biography - BOOTH, JOHN RUDOLPHUS - Volume XV (19211930) - Dictionary of Canadian Biography." Biography - BOOTH, JOHN RUDOLPHUS - Volume XV (1921-1930) - Dictionary of Canadian Biography. http://biographi. ca/en/bio/booth_john_rudolphus_15E.html (accessed November 17, 2013).

Brandt, Mark. "National Treasure: The Chaudière District in Canada's Capital." Heritage Ottawa Newsletter 33, no. 2 (2006). http://heritageottawa. org/en/national_treasure_chaudière_district_canada's_capital (accessed November $15,20 \overline{1} 3$ ).

Borden, Iain. Strangely familiar: narratives of architecture in the city. London: Routledge, 1996.

Borden, Iain. Skateboarding, space and the city: architecture and the body. Oxford:Berg, 2001 . 
CBC News. "Skate park arsonist caught on camera? VPD releases video - British

Columbia- CBC News." CBC News British Columbia. http://www.cbc.ca/news/

canada/british-columbia/skatepark-arsonist-caught-on-camera-vpd-releasesvideo-1.2515802 (accessed March 19, 2014).

Coates, Nigel. Narrative architecture. Chichester, West Sussex: Wiley, 2012.

Carter, Beth. "Spreading Joy in Afghanistan and Cambodia, One Skateboard at a Time." Wired.com. http://www.wired.com/playbook/2012/11/skateistan-2 (accessed March 18, 2014).

"Domtar Won't Dictate Fate of Falls." The Ottawa Citizen, Jun 17, 1998 accessed November 17, 2013. http://search.proquest.com/ docview/240165831?accountid=9894.

"DC Shoes gifts $\$ 1$ million to the city of Philadelphia in hopes of reopening LOVE Park to skateboarders" DC Shoes Inc. press release, June 1, 2004, on the Free LOVE Park website, http://www.ushistory.org/lovepark/media/dcshoes.htm, accessed March 19, 2014.

Dumont, Albert. "The Kettle of Boiling Waters: Chaudĩ̃"re Falls, Algonquin Territory." Turtle Moons Contemplations. http://albertdumont.com/the-kettleof-boiling- waters-chaudiere-falls-algonquin-territory/(accessed March 21 , $2014)$.

Eisenhour, Mackenzie. 2012. "10 DIV SPOTS." Transworld Skateboarding 30, no. 3: 032. Masterfile Premier, EBSCOhost (accessed November 24, 2013). 
Elliot, Bruce S.. "PHILEMON WRIGHT (1760-1839)." Up the Gatineau! 26 (2000). http://www.gvhs.ca/publications/utga-philemon-wright.html (accessed November $15,2013)$.

Encyclopædia Britannica Online, s. v. "skateboarding", accessed November 24, 2013, http://www.britannica.com/EBchecked/topic/547332/skateboarding.

Higgins, Matt. "In Board Sports, Insider Status Makes Gear Sell." New York Times, November 24, 2006.

"Home - Skateparktour.ca." Skateparktour.ca. http://skateparktour.ca/index. php (accessed November 28, 2013).

Howell, Ocean. "Skatepark As Neoliberal Playground: Urban Governance, Recreation Space, And The Cultivation of Personal Responsibility." Space and Culture 11, no. 4 (2008): 47-496.

Howell, Ocean "The 'Creative Class' and the Gentrifying City: Skateboarding in Philadelphia's Love Park," The Journal of Architectural Education (2005); $32-42$.

Hupp, Dave. "Burnside History." The Burnside Project. http://www. burnsideproject.blogspot.ca/ (accessed December 14, 2013).

Iwata, Edward. "Executive Suite: Tony Hawk leaps to top of financial empire." USA Today, March 9, 2008. http://usatoday30.usatoday.com/money/companies/ management/2008-03-09-tony-hawk-entrepreneur_N.htm(accessed December 14, 2013). 
Johns, Judith A. "The relationship between involvement in unstructured unsupervised leisure and substance use in a cohort of adolescent male skateboarders." Electronic Thesis or Dissertation. Kent State University, 2011. https://etd.ohiolink.edu/

Kyle, Susan B., Michael L. Nance, George W. Rutherford Jr., and Flaura K. Winston. "Skateboard-Associated Injuries: Participation-Based Estimates and Injury Characteristics." The Journal of Trauma Injury, Infection, and Critical Care. 53 (2002): 686-90.

"LEESIDE FUNDRAISER $3 / 3$ at astorio's sunday... - Antisocial Skateboard Shop." Antisocial Skateboard Shop. http://antisocialshop.com/ post/78184984456/leesidefundraiser-3-3-at-astorios-sunday (accessed March 19, $2014)$.

"Leeside Tunnel skateboard park." City of Vancouver Official Website. https:// vancouver.ca/parks-recreation-culture/leeside-tunnel-skateboard-park.aspx (accessed March 19, 2014).

Love Story: The Saga of a Skateboard Landmark (Web Video, 2004) Accessed December 02, 2012 http://vimeo.com/866431

"Lumber." Trinity Western University - Laurentian Leadership Centre Heritage. http://twu.ca/sites/laurentian/heritage/lumber.html (accessed November 17, 2013).

McConnell, Fred. "Skate park and classrooms for 1,000 children in Mazar-eSharif." theguardian.com. http://www.theguardian.com/world/2014/mar/06/sp-a-skatepark-and-classrooms-for-1000-children-in-mazar-e-sharif\#comments (accessed March 18, 2014). 
Meiszner, Peter. "Police release surveillance video after vandals

destroy East Vancouver skate park." Global News.http://globalnews.ca/ news/1107682/1107682/(accessed March 19, 2014).

Mika, Nick, and Helma Mika. Bytown, the early days of Ottawa. Belleville, Ont: Mika Pub. Co., 1982 .

Morrison, James. "Algonquin History in the Ottawa River Watershed." in A Background Study for Nomination of the Ottawa River Under the Canadian Heritage Rivers System. Petawawa: Ottawa River Heritage Designation Committee, 2005. http://www.ottawariver.org/pdf/0-ORHDC.pdf (accessed March $19,2014)$

Mullen, Rodney. "How context shapes content," TEDxUSC video, 17:46, filmed May 2012, posted June 2012, http://youtu.be/gwjlDBjNzXk

New York Times, "Homemade Skate Park," November 13, 1994. http://www. nytimes.com/1994/11/13/magazine/sunday-november-13-1994-homemade-skate-park. html (accessed March 19, 2014).

Ottawa Citizen. "Chaudière Falls at the heart of Ottawa's history." Ottawa Citizen, July 30, 2005. http://www.canada.com/story print.html?id=abc57a82a $4 \mathrm{db}-40698 \mathrm{fcc}-1176949 e a 054$ (accessed March 4, 2013).

Oxford English Dictionary. 2nd ed. 20 vols. Oxford: Oxford University Press, 1989 .

Oyelowo, Oyeyinka. "Fate of Chaudière property uncertain."Centretown News (Ottawa), April 6,2012. http://www.centretownnews.ca/indexphp?option=com_ content\&task=view\&id=3167\&Itemid=113 (accessed April 13, 2013). 
Padolsky, Barry, "J.R. Booth Board Mill: Existing conditions and potential for future public use,"Eriksson Padolsky Architects, December 1984

Payne, Elizabeth. "Domtar buildings need heritage protection, architect says." The Ottawa Citizen, July 29, 2013. http://www.ottawacitizen.com/news/ottawa/ Domtar+buildings+need+heritage+protection+architect+says/8722740/story. html (accessed September 21, 2013).

Payne, Elizabeth. "Domtar lands cleanup won't be too costly, environmental assessment suggests." Ottawa Citizen, August 9, 2013. http://www.ottawacitizen.com/technology/ Domtar+lands+cleanup+costly+environmental+assessment+suggests/8770260/story . html (accessed November 18, 2013).

Robinson, Matthew. "Leeside Skate Park, Lee's Domain." The Tyee. http:// thetyee.ca/News/2011/09/28/Leeside-Skate-Park (accessed December 14, 2013).

"PROPOSAL FOR A SPECIAL NATIONAL HISTORIC CENTRE AT ASINABKA/CHAUDIÈRE FALLS, OTTAWA, CANADA," Circle of All Nations press release, n.d. on the Asinabka website. http://www.asinabka.com/Marketing \%20Material/ ASINABKABNbrochureFinalFrenchEng.pdf, accessed March 21, 2014.

"Skateistan | Skateboard NGO for children in Afghanistan, Cambodia." Skateistan. http://www.skateistan.org/ (accessed March 18, 2014).

"Skater's Eye." Thrasher, March 1, 1997.71.

"Skateboarding parks." City of ottawa. http://ottawa.ca/en/residents/parksand-recreation/parks-and-sports-fields/skateboarding-parks (accessed November $28,2013)$. 
"Skateboard parks." City of Vancouver Website. http://vancouver.ca/parksrecreation-culture/skateboard-parks.aspx(accessed November 28, 2013).

Smith, Teresa. "No shelter for skateboarders." Ottawa Citizen, January 1, 2013. http://www.ottawacitizen.com/sports/shelter+skateboarders/7762534/ story.html (accessed November 26, 2013).

Thompson, Catharine Ward. "Places to be wild in nature." In Urban Wildscapes. ed Anna Jorgensen and Richard Keenan London: Routledge, 2012.

The Canadian Manufacturer's Association. "Business and History - The E. B. Eddy Company." Western Libraries Company Information Canada. http://www.lib. uwo.ca/programs/companyinformationcanada/ccc-ebeddy.html (accessed November $17,2013)$.

Under the Bridge. Film. Directed by Jake Phelps. San Francisco, CA: High Speed Productions, 2010.

Vancouver Parks and Recreation, Skateboard Strategy for Vancouver, (Vancouver: Unknown, 2005), http://vancouver.ca/files/cov/2005-SkateboardStrategy.pdf

Vivoni, F. "Spots of Spatial Desire: Skateparks, Skateplazas, And Urban Politics." Journal of Sport \& Social Issues 33, no. 2 (2009): 130-49

Windmill Development. "WINDMILL DEVELOPMENT GROUP SIGNS AGREEMENT TO PURCHASE DOMTAR GATINEAU AND OTTAWA LANDS." December 4, 2013.

Woods, Shirley E.. Ottawa, the capital of Canada. Toronto: Doubleday Canada, 1980. 